\title{
Polarization-Corrected Temperatures for 10-, 19-, 37-, and 89-GHz Passive Microwave Frequencies
}

\author{
DANIEL J. CECIL \\ NASA George C. Marshall Space Flight Center, Huntsville, Alabama \\ THEMIS CHRONIS \\ University of Alabama in Huntsville, Huntsville, Alabama
}

(Manuscript received 19 January 2018, in final form 15 June 2018)

\begin{abstract}
Coefficients are derived for computing the polarization-corrected temperature (PCT) for 10-, 19-, 37- and 89-GHz (and similar) frequencies, with applicability to satellites in the Global Precipitation Measurement mission constellation and their predecessors. PCTs for 10- and 19-GHz frequencies have been nonexistent or seldom used in the past; developing those is the main goal of this study. For 37 and $89 \mathrm{GHz}$, other formulations of PCT have already become well established. We consider those frequencies here in order to test whether the large sample sizes that are readily available now would point to different formulations of PCT. The purpose of the PCT is to reduce the effects of surface emissivity differences in a scene and draw attention to ice scattering signals related to precipitation. In particular, our intention is to develop a PCT formula that minimizes the differences between land and water surfaces, so that signatures resulting from deep convection are not easily confused with water surfaces. The new formulations of PCT for 10- and 19-GHz measurements hold promise for identifying and investigating intense convection. Four examples are shown from relevant cases. The PCT for each frequency is effective at drawing attention to the most intense convection, and removing ambiguous signals that are related to underlying land or water surfaces. For 37 and $89 \mathrm{GHz}$, the older formulations of PCT from the literature yield generally similar values as ours, with the differences mainly being a few kelvins over oceans. An optimal formulation of PCT can depend on location and season; results are presented here separated by latitude and month.
\end{abstract}

\section{Introduction}

Satellite-borne passive microwave imagers provide information on the characteristics of Earth's surface, its overlying atmosphere, and precipitation. Warm brightness temperatures can result from high emissivity land surfaces or from emission by liquid cloud or rain hydrometeors aloft. Low brightness temperatures can result from low emissivity surfaces, such as ice and water bodies, or from scattering by large precipitation ice particles. Interpretation of the cause of a low brightness temperature can be ambiguous because it could result from scattering by graupel or hail in a convective storm, or from a wet or water-covered surface. The interpretation is especially difficult when an overland scene includes convective storms, inland water bodies, and potentially even floodwater or wet soil from recent precipitation (Fig. 1). This paper aims to enable more

Corresponding author: Daniel J. Cecil, daniel.j.cecil@nasa.gov straightforward assessment of the impacts of hydrometeors on passive microwave measurements, by minimizing effects due to variability in the underlying surface.

An example of the ambiguity in discriminating storms from surface conditions is shown in Fig. 1. Strong convective storms are depicted by radar in Fig. 1a, and some of them produce lower brightness temperatures than the adjacent land scenes in Figs. 1b-d, especially in the 37-GHz channel (and at higher frequencies, which are not shown here). For the lower frequencies, most of the stormassociated brightness temperatures are no lower than the precipitation-free brightness temperatures over the nearby Gulf of Mexico (bottom-right portion of each panel). Over the eastern part of Texas, there are several small areas with reduced brightness temperatures that do not correspond to storms in the radar image. Instead, they are associated with lakes.

Most current imagers have separate horizontally polarized and vertically polarized channels for most frequencies, particularly for frequencies near 10, 19, 37, 


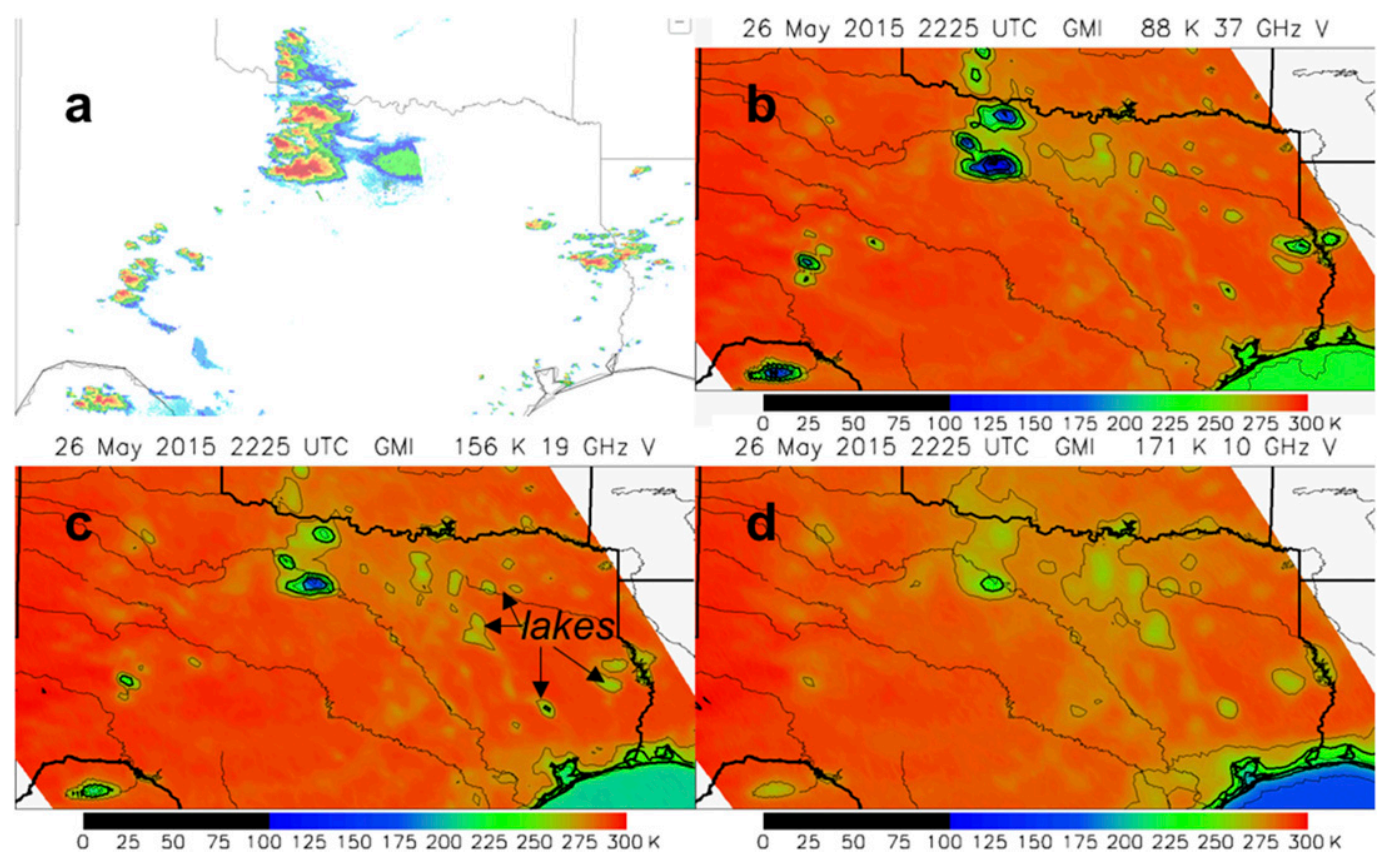

FIG. 1. Example convective outbreak in Texas at 2225 UTC 26 May 2015. (a) Ground-based radar reflectivity mosaic. GMI (b) 37-, (c) 19-, and (d) 10-GHz vertically polarized brightness temperatures. Contour interval in (b)-(d) is $25 \mathrm{~K}$, with thick contours every $50 \mathrm{~K}$, and the minimum brightness temperature in the domain is printed in the panel title.

and $89 \mathrm{GHz}$. Large polarization differences in the upwelling brightness temperatures typically result from water surfaces and surfaces with high soil moisture. Scattering by large ice hydrometeors typically leads to much smaller polarization differences. Dry land surfaces also have smaller polarization differences. A linear combination of horizontally polarized and vertically polarized brightness temperatures, termed polarization-corrected temperature (PCT), can remove much of the effect from varying land surface characteristics (Weinman and Guetter 1977; Grody 1984; Spencer et al. 1989; Barrett and Kidd 1990; Todd and Bailey 1995; Kidd 1998; Toracinta et al. 2002). The PCT is then useful for identifying scenes with precipitation, with less ambiguity related to the underlying surface type or surface conditions. Formulas for PCT have been presented in various forms in the literature, but here we follow the form

$$
\mathrm{PCT}_{f}=\left(1+\Theta_{f}\right) \mathrm{TB}_{f \mathrm{~V}}-\Theta_{f} \mathrm{~TB}_{f \mathrm{H}},
$$

where $\Theta$ is a coefficient that minimizes the effects of surface emissivity and TB is the brightness temperature at frequency $f$ and vertical $(\mathrm{V})$ or horizontal $(\mathrm{H})$ polarization).

Spatial resolution and sensitivity to typical graupel sizes both increase with the increasing frequency (decreasing wavelength) of the radiation. As such, much of the work involving passive microwave PCT has focused on channels in the $85-91-\mathrm{GHz}$ range, with some attention also given to channels near $37 \mathrm{GHz}$. The Spencer et al. (1989) $\mathrm{PCT}_{85}$ is probably the most widely used today, with the coefficient $\Theta_{85}=0.818$ derived from several days of Special Sensor Microwave Imager (SSM/I; Hollinger et al. 1990) global observations of cloud-free oceanic areas. Before settling on this value for $\Theta_{85}$, Spencer et al. (1989) also discussed model calculations that imply values in the range of $0.54-0.61$, but those values did not work well with the observed SSM/I data. The Spencer et al. (1989) formula was subsequently used in databases of mesoscale convective systems (Mohr and Zipser 1996) and more general precipitation features (Nesbitt et al. 2000; Liu et al. 2008), and numerous related studies.

Although Spencer et al. (1989) identified a constant $\Theta_{85}$ value in order to apply a uniform standard for global analysis, others have emphasized that optimal choices of $\Theta_{85}$ can be a function of location, season, and local conditions. Barrett and Kidd (1990) proposed $\Theta_{85}=0.64$ for northwestern Europe and the United Kingdom during summer and autumn. Todd and Bailey (1995) and Kidd (1998) empirically derived $\Theta_{85}$ values separately for each scene (each SSM/I overpass of the United Kingdom), allowing $\Theta_{85}$ to vary from day to day. Their $\Theta_{85}$ values generally ranged from about 0.5 to 0.75 . Kidd (1998) showed large daily and intraday variations superimposed 
on an apparent annual cycle for $\Theta_{85}$, with lowest values in winter and highest values in summer. Todd and Bailey (1995) and Kidd (1998) argued that allowing $\Theta_{85}$ to vary with local conditions is important for distinguishing light rain from rain-free regions.

Before the first SSM/I was launched with its $85-\mathrm{GHz}$ frequency in $1987,37-\mathrm{GHz}$ measurements were used from the Nimbus-6 Electrically Scanning Microwave Radiometer (ESMR) and Scanning Multichannel Microwave Radiometer (SMMR). Weinman and Guetter (1977) developed a linear transformation (they did not use the term PCT) for use with ESMR. Their Eq. (16) uses $\Theta_{37}=1.2$ based on theory and $\Theta_{37}=1.5$ based empirically on ESMR observations. Grody (1984) derived $\Theta_{37}=1.08$ and $\Theta_{19}=1.38$ for SMMR. Toracinta et al. (2002) used $\Theta_{37}=1.2$ for the Tropical Rainfall Measuring Mission (TRMM; Kummerow et al. 1998) precipitation feature database (Liu et al. 2008), using TRMM Microwave Imager (TMI) data. That value continues to be used for Global Precipitation Measurement (GPM; Hou et al. 2014) mission precipitation features. Lee et al. (2002) used $\Theta_{37}=1.18$, and that value continues to be used for the popular Naval Research Laboratory-Monterey tropical cyclone web page. Jiang et al. (2018) provide a nice discussion of $\mathrm{PCT}_{37}$ and use it to interpret precipitation types in tropical cyclones.

Precipitation estimation, and more specifically the discrimination between raining and nonraining areas, motivated much of the aforementioned research involving PCT $_{85}$. Cecil et al. (2005) and Zipser et al. (2006) emphasized the use of $\mathrm{PCT}_{37}$ in studies of intense thunderstorms, using TRMM measurements. Cecil (2009) empirically related TRMM $\mathrm{PCT}_{85}$ and $\mathrm{PCT}_{37}$ to reports of large hail reaching the surface, and Cecil and Blankenship (2012) applied the $\mathrm{PCT}_{37}$-hail relationship to Advanced Microwave Scanning Radiometer for Earth Observing System (AMSR-E) PCT $_{36}$ [using the same $\Theta_{37}$ as in Toracinta et al. (2002)] in order to estimate a global climatology of hailstorm occurrence. Cecil (2009) also noted that 19-GHz measurements from TRMM are more effective at giving a high-confidence indication of large hail, although relatively coarse spatial resolution and the lack of a well-established $\mathrm{PCT}_{19}$ made it more difficult to use. Mroz et al. (2017) tested an early version of the $\mathrm{PCT}_{19}$ that is presented here and found it to be more effective for identifying hail than any of the other GMI frequencies. We did not have a version of $\mathrm{PCT}_{10}$ ready for inclusion in the Mroz et al. study, but even without applying the PCT, the low-resolution $10-\mathrm{GHz}$ measurements did show some usefulness in that study.

This paper is motivated by observations of reduced brightness temperatures in the TRMM and GPM 19and $10-\mathrm{GHz}$ channels for some intense thunderstorms, besides the reduced brightness temperatures that have already been well documented for the 85-89- and 3637-GHz frequencies. Systematic analysis of thunderstormrelated signatures in the $19-$ and $10-\mathrm{GHz}$ channels is difficult without first applying a PCT transformation to those channels. This paper empirically derives values for $\Theta_{10}, \Theta_{19}, \Theta_{37}$, and $\Theta_{89}$ from 3 years of GPM measurements and considers their spatial and seasonal variability. The main goal is to derive and evaluate useful coefficients for $\mathrm{PCT}_{10}$ and $\mathrm{PCT}_{19}$, since those have rarely been used in the past. The values for $\Theta_{37}$ and $\Theta_{89}$ from the literature have proven effective over the years. We reexamine them here because it has become convenient to apply our methods to vastly larger sample sizes than were used in the previous studies. Our optimal coefficients (producing the smallest contrast between land and water surfaces, and thus less ambiguity related to surface type) for $\mathrm{PCT}_{37}$ and $\mathrm{PCT}_{89}$ are slightly different from those that have already been widely used. Our analysis shows that a broad range of coefficient values can be defensible for these frequencies, when applied to global studies. As such, there may be little practical benefit for many users in switching from the previous $\Theta_{37}$ and $\Theta_{89}$ values to our marginally more effective values. The values derived for $\Theta_{10}$ and $\Theta_{19}$ do show promise for enabling improved analysis of vigorous, deep convection.

\section{Data and methods}

GPM Microwave Imager (GMI) version V05A brightness temperatures (GES DISC 2016) from 1 April 2014 to 31 March 2017 are used for development of PCT coefficients in this study. Every other GPM orbit (oddnumbered orbits from 503 to 17553 ) and every 10th scan position (of the 221 positions per GMI scan) are used, in order to speed up the required processing. This amounts to using $5 \%$ of the available data during a 3-yr period, while still sampling a broad variety of conditions.

The GMI level 2 ("GPROF") files (Iguchi and Meneghini 2016) are further used to identify precipitation-free pixels, and to classify each pixel as land (GPROF surface types 3-5, corresponding to "maximum vegetation," "high vegetation," and "moderate vegetation") or ocean (GPROF surface type 1). The "ocean" classification can include large water bodies, for example, the Great Lakes. Sea ice, arid regions, surface snow cover, rivers, coasts, and precipitation scenes are excluded.

Each orbit is divided into $5^{\circ}$ latitude bins. Statistics are derived separately for each of these bins that has at least 10 land and 10 water pixels without precipitation. Latitude bins without enough land and water pixels in a given orbit are ignored, because a comparison between land and water pixels is required for building the empirical relationships. For a given latitude bin in a given GPM 
TABLE 1. Sample size (in millions) of land-water pairings for each $5^{\circ}$ latitude bin (bottom latitude of the bin is listed in the first column) and each month.

\begin{tabular}{|c|c|c|c|c|c|c|c|c|c|c|c|c|}
\hline Lat $\left(^{\circ}\right)$ & Jan & Feb & Mar & Apr & May & Jun & Jul & Aug & Sep & Oct & Nov & Dec \\
\hline 55 & 2 & 4 & 17 & 136 & 273 & 293 & 338 & 357 & 308 & 200 & 38 & 6 \\
\hline 50 & 6 & 8 & 26 & 153 & 209 & 225 & 241 & 255 & 221 & 164 & 53 & 11 \\
\hline 45 & 12 & 21 & 65 & 133 & 159 & 173 & 180 & 193 & 165 & 143 & 85 & 29 \\
\hline 40 & 43 & 47 & 91 & 112 & 118 & 119 & 127 & 133 & 120 & 115 & 96 & 62 \\
\hline 35 & 81 & 75 & 112 & 122 & 128 & 129 & 125 & 128 & 116 & 117 & 109 & 96 \\
\hline 30 & 72 & 68 & 86 & 87 & 89 & 84 & 82 & 86 & 80 & 79 & 87 & 87 \\
\hline 25 & 78 & 70 & 82 & 75 & 69 & 61 & 52 & 53 & 60 & 60 & 74 & 84 \\
\hline 20 & 75 & 71 & 86 & 76 & 73 & 65 & 40 & 34 & 38 & 45 & 60 & 73 \\
\hline 15 & 58 & 59 & 73 & 68 & 58 & 45 & 36 & 37 & 38 & 32 & 45 & 55 \\
\hline 10 & 108 & 111 & 120 & 101 & 92 & 85 & 72 & 77 & 86 & 82 & 89 & 100 \\
\hline 5 & 104 & 112 & 123 & 95 & 96 & 94 & 91 & 95 & 91 & 89 & 98 & 100 \\
\hline 0 & 103 & 97 & 101 & 86 & 98 & 97 & 98 & 108 & 108 & 102 & 100 & 100 \\
\hline-5 & 86 & 80 & 80 & 72 & 92 & 91 & 95 & 103 & 100 & 95 & 91 & 88 \\
\hline-10 & 85 & 80 & 84 & 83 & 103 & 102 & 110 & 121 & 119 & 111 & 103 & 89 \\
\hline-15 & 89 & 83 & 90 & 94 & 120 & 113 & 121 & 132 & 130 & 124 & 108 & 94 \\
\hline-20 & 81 & 78 & 85 & 86 & 104 & 95 & 99 & 108 & 114 & 104 & 99 & 86 \\
\hline-25 & 77 & 75 & 79 & 79 & 95 & 84 & 87 & 92 & 93 & 82 & 82 & 77 \\
\hline-30 & 76 & 72 & 74 & 78 & 95 & 83 & 85 & 90 & 91 & 81 & 83 & 76 \\
\hline-35 & 90 & 88 & 83 & 86 & 97 & 88 & 89 & 93 & 97 & 88 & 95 & 91 \\
\hline-40 & 50 & 48 & 47 & 45 & 46 & 42 & 41 & 41 & 44 & 41 & 48 & 52 \\
\hline-45 & 28 & 27 & 26 & 26 & 25 & 22 & 20 & 20 & 22 & 23 & 26 & 28 \\
\hline-50 & 17 & 16 & 16 & 16 & 17 & 13 & 12 & 12 & 16 & 15 & 16 & 18 \\
\hline-55 & 6 & 5 & 6 & 6 & 6 & 5 & 3 & 3 & 5 & 5 & 5 & 6 \\
\hline
\end{tabular}

orbit, candidate PCT values using a given $\Theta$ are computed for each pixel. The differences between PCT values are then computed for every possible pairing of land and water pixels within that latitude bin. If there are 10 land and 10 water pixels, for example, there would be 100 pairs with land-water PCT differences. Since the GMI swath is about $900 \mathrm{~km}$ wide and the satellite only takes a few minutes to traverse $5^{\circ}$, most of the land-water differences are computed within a few hundred kilometers and a few minutes of each other. Ideally, a perfect choice of $\Theta$ would yield PCT differences near zero for all possible land-water pairings, and a poor choice of $\Theta$ would yield large PCT differences. That ideal scenario is not realistic, because inhomogeneities in a scene besides surface type would give nonzero differences. A histogram of PCT differences is computed from the land-water pairings and added to histograms computed from other orbits. This process is repeated for candidate PCT values computed with $\Theta$ ranging from 0.3 to 1.79 in increments of 0.01 . Each GMI frequency under consideration is treated separately, at its native resolution.

The PCT difference histograms are computed with bin size of $2 \mathrm{~K}$. They are accumulated separately for each $5^{\circ}$ latitude bin, for each month of the year, and for each $\Theta$ value. Even though we considered only $5 \%$ of the available GMI data, before further restricting the data by surface type and precipitation, most latitudes (from $55^{\circ} \mathrm{S}$ to $60^{\circ} \mathrm{N}$ ) and months contain tens of millions of land-water pairings for the resulting histograms. The sample size (Table 1) is relatively small at far the southern latitudes because there is so little land there, and is large at the far northern latitudes because of both orbital geometry and the mix of land and ocean surfaces. The seasonal variation in sample size is extreme at far northern latitudes ( 2 million land-water pairings in January, 357 million pairings in August) because the surface snow and ice cover are eliminated.

The resulting histograms of land-water PCT differences are analyzed in section 3 to determine which $\Theta$ values most consistently yield small PCT differences. A small difference in PCT between land and water pixel pairs indicates that the surface type is not strongly influencing the PCT, and that we can use PCT to investigate precipitation hydrometeor signatures instead. Section 3a accumulates the histograms into probability density functions across all latitudes and months for a global analysis, and section $3 b$ examines variability by latitude and month.

PCT coefficients based on the results from section 3 are applied to selected cases in section 4 . Those cases were observed individually by the GMI, TMI, AMSR-E, and SSM/I sensors (Table 2). The GPM Intercalibration (X-CAL) Working Group dataset (Berg et al. 2016; GES DISC 2016, 2017a,b,c) is used for these, since it applies an intercalibration among sensors, making their calibrations consistent with GMI. The X-CAL brightness temperatures are referred to as GPM level $1 \mathrm{C}$ version $05 \mathrm{~A}$, with 
TABLE 2. Footprint sizes (effective fields of view; $\mathrm{km}$ ) for the frequencies and instruments used in this study.

\begin{tabular}{|c|c|c|c|c|c|c|c|c|c|c|c|c|c|c|c|}
\hline \multirow{2}{*}{$\frac{\text { Sensor }}{\text { Frequency }(\mathrm{GHz})}$} & \multicolumn{4}{|c|}{$\begin{array}{l}\text { GMI (Hou } \\
\text { et al. 2014) }\end{array}$} & \multicolumn{4}{|c|}{$\begin{array}{l}\text { TMI (Kummerow } \\
\text { et al. 1998) }\end{array}$} & \multicolumn{4}{|c|}{$\begin{array}{c}\text { AMSR-E } \\
\text { (JAXA 2006) }\end{array}$} & \multicolumn{3}{|c|}{$\begin{array}{l}\text { SSM/I (Hollinger } \\
\text { et al. 1990) }\end{array}$} \\
\hline & 10.65 & 18.7 & 36.5 & 89.0 & 10.7 & 19.35 & 37.0 & 85.5 & 10.65 & 18.7 & 36.5 & 89.0 & 19.35 & 37.0 & 85.5 \\
\hline Along track & 32 & 18 & 15 & 7 & 63 & 30 & 16 & 7 & 51 & 27 & 14 & 6 & 69 & 37 & 15 \\
\hline Cross track & 19 & 11 & 9 & 4 & 37 & 18 & 9 & 5 & 29 & 16 & 8 & 4 & 43 & 28 & 13 \\
\hline
\end{tabular}

other satellites included as GPM constellation members. GPM level 1B version 05A 85-GHz data (GES DISC 2017d) are also used for the TMI case, because level 1C unnecessarily sets values below $50 \mathrm{~K}$ as missing. AMSR-E level 2A version 3 files (Ashcroft and Wentz 2013) from the National Snow and Ice Data Center (NSIDC) are also used for $89 \mathrm{GHz}$ for the same reason.

\section{Results: Optimizing PCT coefficients}

\section{a. Global analysis}

First, we consider statistics from the land-water PCT differences accumulated over all months and all regions. Since a motivation for using the PCT is to eliminate the land-water differences as much as possible, Fig. 2 shows what percentage of land-water pairs have PCT differences below $2 \mathrm{~K}$ (thick lines) and below $10 \mathrm{~K}$ (thin lines) as a function of the choice of $\Theta$ value. For convenience, we will refer to the value yielding land-water PCT differences less than $2 \mathrm{~K}$ the most often as the "best" performing $\Theta$ in a given analysis. These are not the $\Theta$ values we ultimately recommend using. Defining the best $\Theta$ based on how rarely it produces large $(>10 \mathrm{~K})$ differences would lead to $\Theta$ values $0.03-0.04$ higher. Our ultimate recommendations will consider both those definitions and the regional and seasonal variability to be addressed in section $3 \mathrm{~b}$.

Figure 3 shows probability density functions of landwater PCT differences for the $\Theta$ values that yield PCT differences of less than $2 \mathrm{~K}$ most often and for some other $\Theta$ values from the literature. For $\Theta_{89}=0.63,24 \%$ of land-water pairings have PCT differences less than $2 \mathrm{~K}$, another $21 \%$ have differences between 2 and $4 \mathrm{~K}$, and $16 \%$ have differences of $4-6 \mathrm{~K}$. Using $\Theta_{89}=0.82$ based on Spencer et al. (1989) reduces those percentages to $18 \%, 17 \%$, and $16 \%$, respectively. The bestperforming $\Theta_{37}$ (1.10) in this global analysis yields land-water differences in $\mathrm{PCT}_{37}$ that are slightly larger than the differences in $\mathrm{PCT}_{89}$ based on using the Spencer et al. $\Theta_{85}$. In other words, a suboptimal choice of $\Theta_{89}$ can outperform an optimal choice of $\Theta_{37}$. Moving to still lower-frequency channels, the best-performing $\Theta_{19}(1.36)$ and $\Theta_{10}(1.48)$ are progressively less effective at minimizing the land-water PCT differences. This decreasing

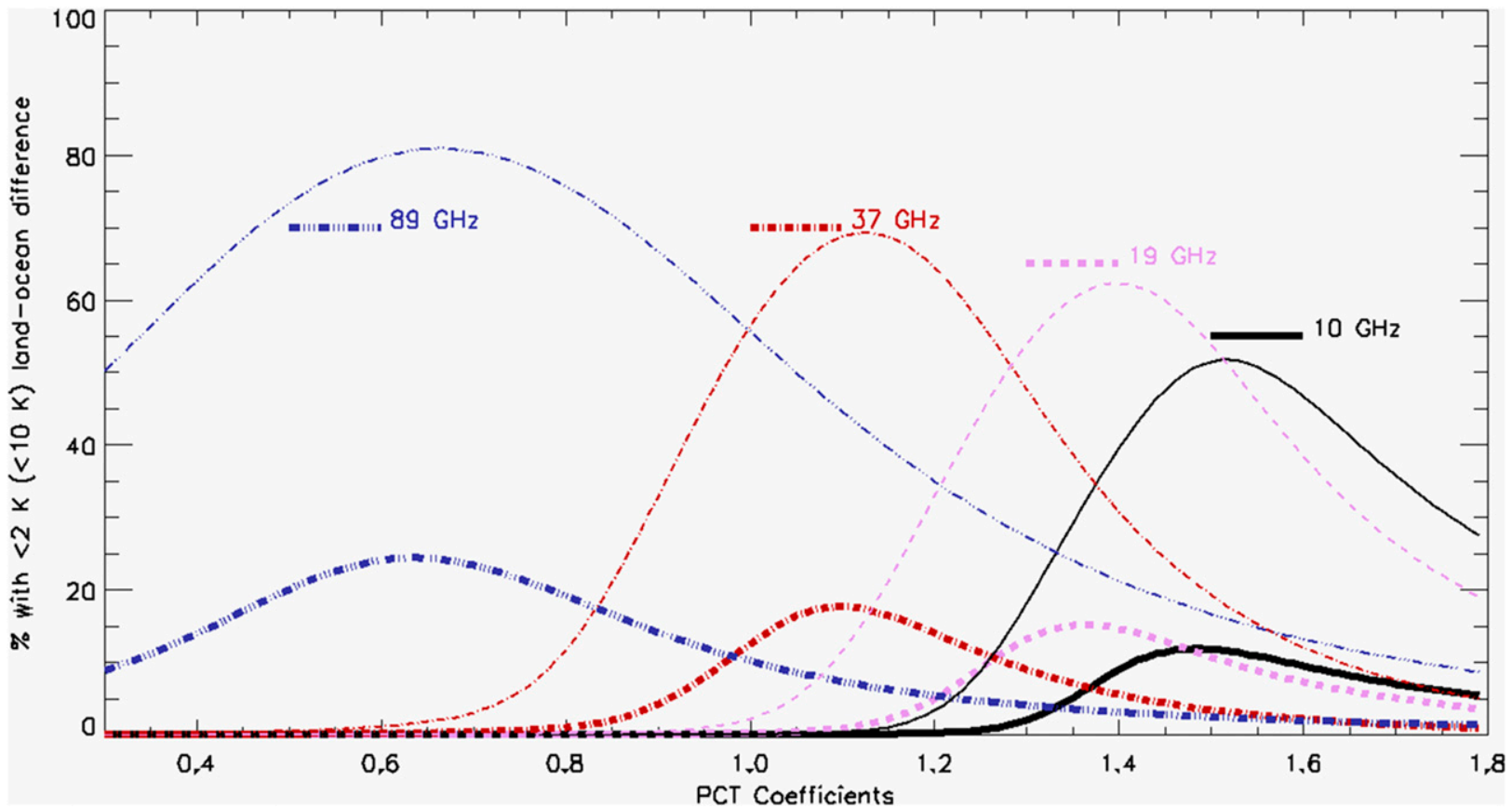

FIG. 2. Percentage of land-water PCT differences less than $2 \mathrm{~K}$ (thick lines) and less than $10 \mathrm{~K}$ (thin lines), as a function of $\Theta$ value. 


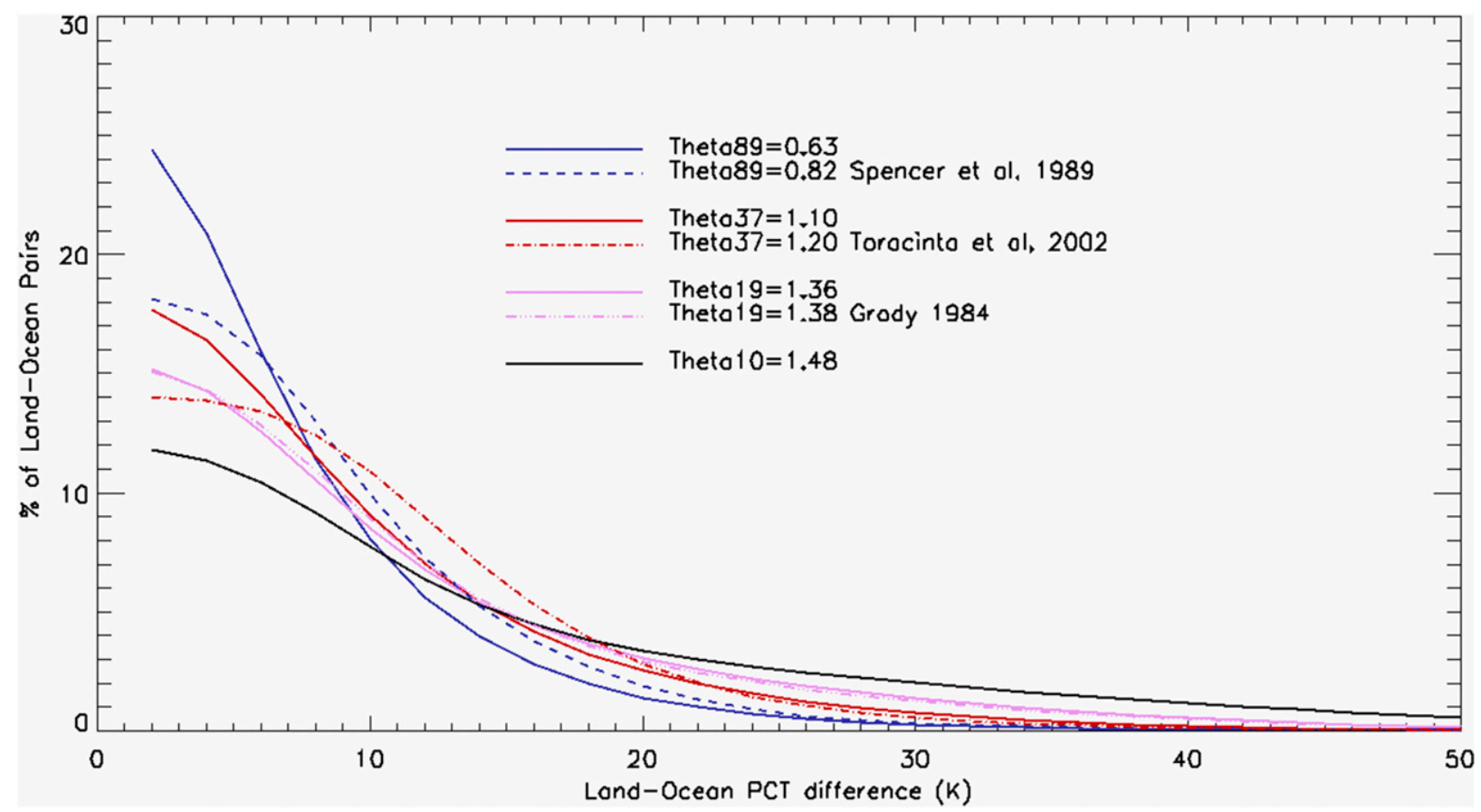

FIG. 3. Probability density functions of the land-water PCT difference (bin size $=2 \mathrm{~K}$ ) for selected PCT coefficients $\Theta$.

effectiveness with decreasing frequency is also seen in Fig. 2. The Toracinta et al. (2002) coefficient $\Theta_{37}=1.20$ yields land-water $\mathrm{PCT}_{37}$ differences less than $2 \mathrm{~K} 14 \%$ of the time and between 2 and $4 \mathrm{~K}$ another $14 \%$ of the time.
This is comparable to $\Theta_{19}=1.36$, yielding $\mathrm{PCT}_{19}$ differences less than $2 \mathrm{~K} 15 \%$ of the time and $2-4 \mathrm{~K} 14 \%$ of the time. For $\Theta_{10}=1.48$, only $12 \%$ of land-water pairs have $\mathrm{PCT}_{10}$ differences less than $2 \mathrm{~K}$ and $11 \%$ between 2 and
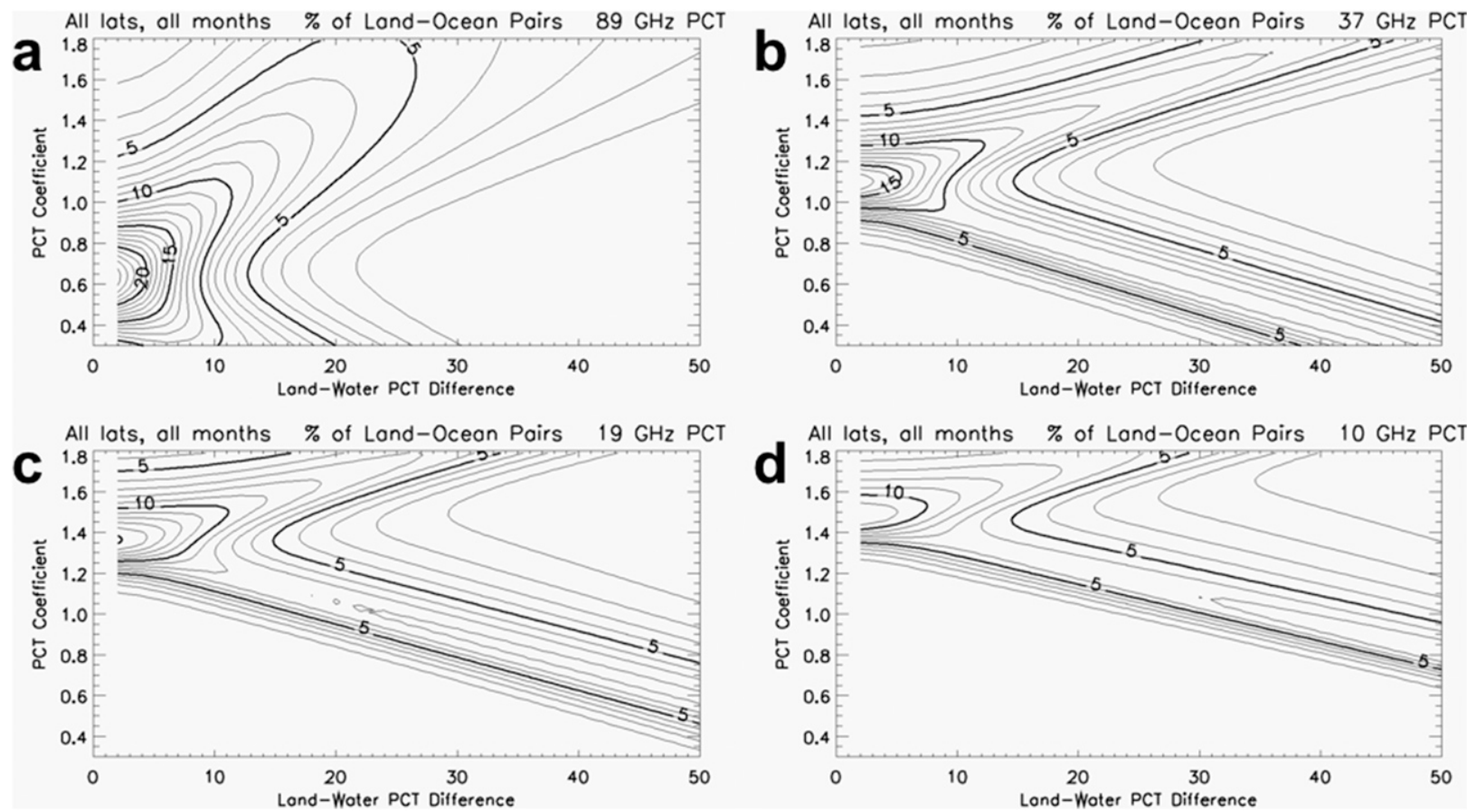

FIG. 4. Two-dimensional probability density functions of the land-water PCT difference (bin size $=2 \mathrm{~K}$ ) for $\Theta$ coefficients ranging from 0.30 to 1.79 (increments of 0.01 ). Contour interval is $1 \%$, with thick lines at $5 \%$ intervals. 
TABLE 3. The 89-GHz PCT coefficient $\Theta_{89}$ for each latitude and month that gives the most land-water pixel pairs with PCT differences $<2 \mathrm{~K}$.

\begin{tabular}{rrrllllllllll}
\hline \hline Lat $\left(^{\circ}\right)$ & Jan & Feb & Mar & Apr & May & Jun & Jul & Aug & Sep & Oct & Nov & Dec \\
\hline 55 & 0.54 & 0.57 & 0.60 & 0.63 & 0.64 & 0.72 & 0.74 & 0.69 & 0.61 & 0.55 & 0.58 & 0.62 \\
50 & 0.52 & 0.53 & 0.56 & 0.60 & 0.64 & 0.80 & 0.74 & 0.72 & 0.63 & 0.55 & 0.56 & 0.57 \\
45 & 0.55 & 0.58 & 0.60 & 0.66 & 0.69 & 0.79 & 0.77 & 0.67 & 0.64 & 0.58 & 0.57 & 0.58 \\
40 & 0.51 & 0.56 & 0.58 & 0.59 & 0.64 & 0.72 & 0.66 & 0.63 & 0.61 & 0.58 & 0.55 & 0.53 \\
35 & 0.48 & 0.55 & 0.55 & 0.63 & 0.65 & 0.75 & 0.67 & 0.66 & 0.62 & 0.57 & 0.51 & 0.48 \\
30 & 0.46 & 0.51 & 0.58 & 0.65 & 0.69 & 0.78 & 0.70 & 0.65 & 0.66 & 0.56 & 0.49 & 0.41 \\
25 & 0.44 & 0.56 & 0.65 & 0.73 & 0.82 & 0.70 & 0.68 & 0.66 & 0.61 & 0.59 & 0.55 & 0.46 \\
20 & 0.51 & 0.57 & 0.70 & 0.83 & 0.81 & 0.74 & 0.64 & 0.51 & 0.54 & 0.58 & 0.56 & 0.51 \\
15 & 0.59 & 0.64 & 0.68 & 0.77 & 0.73 & 0.68 & 0.64 & 0.59 & 0.57 & 0.54 & 0.58 & 0.58 \\
10 & 0.62 & 0.68 & 0.73 & 0.85 & 0.87 & 0.85 & 0.74 & 0.64 & 0.66 & 0.69 & 0.60 & 0.61 \\
5 & 0.65 & 0.71 & 0.73 & 0.69 & 0.66 & 0.63 & 0.57 & 0.53 & 0.58 & 0.61 & 0.62 & 0.61 \\
0 & 0.58 & 0.63 & 0.57 & 0.52 & 0.52 & 0.56 & 0.59 & 0.57 & 0.59 & 0.60 & 0.60 & 0.60 \\
-5 & 0.59 & 0.62 & 0.56 & 0.52 & 0.56 & 0.61 & 0.61 & 0.64 & 0.64 & 0.63 & 0.61 & 0.61 \\
-10 & 0.52 & 0.55 & 0.49 & 0.51 & 0.57 & 0.65 & 0.66 & 0.68 & 0.70 & 0.67 & 0.57 & 0.53 \\
-15 & 0.53 & 0.50 & 0.50 & 0.52 & 0.59 & 0.65 & 0.65 & 0.68 & 0.69 & 0.64 & 0.58 & 0.51 \\
-20 & 0.68 & 0.62 & 0.59 & 0.63 & 0.61 & 0.64 & 0.62 & 0.64 & 0.72 & 0.75 & 0.72 & 0.68 \\
-25 & 0.81 & 0.77 & 0.70 & 0.67 & 0.66 & 0.61 & 0.60 & 0.63 & 0.73 & 0.81 & 0.78 & 0.82 \\
-30 & 0.84 & 0.85 & 0.77 & 0.72 & 0.63 & 0.59 & 0.60 & 0.63 & 0.70 & 0.81 & 0.77 & 0.84 \\
-35 & 0.84 & 0.80 & 0.74 & 0.68 & 0.64 & 0.57 & 0.60 & 0.61 & 0.65 & 0.75 & 0.73 & 0.79 \\
-40 & 0.78 & 0.76 & 0.72 & 0.63 & 0.62 & 0.58 & 0.58 & 0.58 & 0.62 & 0.72 & 0.72 & 0.77 \\
-45 & 0.71 & 0.66 & 0.62 & 0.58 & 0.55 & 0.49 & 0.52 & 0.54 & 0.55 & 0.66 & 0.62 & 0.67 \\
-50 & 0.74 & 0.67 & 0.67 & 0.61 & 0.56 & 0.51 & 0.53 & 0.56 & 0.56 & 0.62 & 0.69 & 0.70 \\
-55 & 0.81 & 0.69 & 0.70 & 0.59 & 0.57 & 0.57 & 0.56 & 0.58 & 0.61 & 0.59 & 0.76 & 0.71 \\
\hline
\end{tabular}

$4 \mathrm{~K}$. For this "best" choice of $\Theta_{10}$ from the global analysis, about half the land-water pairs have $\mathrm{PCT}_{10}$ differences greater than $10 \mathrm{~K}$. Any choice of $\Theta_{10}$ will have many situations where it is not very effective at removing the land-water contrast.

The probability density functions in Fig. 3 isolated the $\Theta$ values that gave the sharpest peaks in the $0-2-\mathrm{K}$ PCT difference bins. Figure 4 instead depicts the performance for all $\Theta$ values, in the form of two-dimensional probability density functions. The sideways $\mathrm{V}$ shapes for these two-dimensional probability density functions indicate that for each frequency, there is a preferred range of $\Theta$ values where the land-water PCT differences tend to be small. Moving away from that preferred range, $\Theta$ values that are too high or too low give larger land-water PCT differences. Minimizing those land-water differences is crucial for seamlessly interpreting the precipitation characteristics across a coastline, or in a scene including small water bodies. A narrow range of $\Theta$ values gives acceptably small land-water PCT differences for the lowfrequency channels, but a broad range of $\Theta_{89}$ values gives small $\mathrm{PCT}_{89}$ differences.

\section{b. Variability by latitude and month}

Figures analogous to Figs. 2-4 were generated separately for each $5^{\circ}$ latitude bin and for each month. Lower $\Theta$ values generally have better performance (i.e., less variation in PCT) in the deep tropics than at higher latitudes. At mid- and high latitudes, higher $\Theta$ values perform better during the warm season and lower $\Theta$ values perform better during the cold season. The $\Theta$ values that yield the highest percentage of land-water pairs with PCT differences less than $2 \mathrm{~K}$ are compiled as functions of latitude and month in Table $3(89 \mathrm{GHz})$, Table 4 $(37 \mathrm{GHz})$, Table $5(19 \mathrm{GHz})$, and Table $6(10 \mathrm{GHz})$.

Just as a range of $\Theta$ values works better for higherfrequency channels than any $\Theta$ value does for lowerfrequency channels in Figs. 2-4, a range of $\Theta$ values also works well in the tropics, compared to higher latitudes. As an example, the effectiveness of each $\Theta$ value at reducing the land-water contrast below $2 \mathrm{~K}$ (thick lines) and below $10 \mathrm{~K}$ (thin lines) as in Fig. 2 is reproduced separately for $0^{\circ}-5^{\circ} \mathrm{N}$ in July (Fig. 5) and for $35^{\circ}-40^{\circ} \mathrm{N}$ in July (Fig. 6). The best-performing $\Theta$ values are lower in the tropics than in the midlatitudes (consistent with Tables 3-6). The PCT is so much more effective at reducing the land-water contrast in the deep tropics, thus there is little need to find the precise $\Theta$ value that gives the best scores there. One could choose whichever $\Theta$ value is most acceptable for the midlatitudes, and that $\Theta$ would also work well in the tropics.

\section{Discussion and examples}

Consideration of Figs. 2-4, analogous figures that are segregated by latitude and month, and Tables 3-6 leads 
TABLE 4. As in Table 3, but for the 37-GHz PCT coefficient $\Theta_{37}$.

\begin{tabular}{|c|c|c|c|c|c|c|c|c|c|c|c|c|}
\hline Lat $\left(^{\circ}\right)$ & Jan & Feb & Mar & Apr & May & Jun & Jul & Aug & Sep & Oct & Nov & Dec \\
\hline 55 & 0.97 & 0.98 & 1.01 & 1.03 & 1.03 & 1.11 & 1.12 & 1.10 & 1.05 & 0.98 & 0.98 & 1.00 \\
\hline 50 & 0.96 & 0.97 & 0.99 & 1.03 & 1.07 & 1.17 & 1.13 & 1.13 & 1.08 & 1.02 & 1.00 & 0.98 \\
\hline 45 & 0.98 & 1.01 & 1.03 & 1.07 & 1.11 & 1.17 & 1.18 & 1.14 & 1.11 & 1.04 & 1.02 & 1.00 \\
\hline 40 & 0.97 & 1.01 & 1.01 & 1.03 & 1.09 & 1.15 & 1.12 & 1.12 & 1.09 & 1.05 & 1.01 & 0.99 \\
\hline 35 & 0.95 & 1.01 & 1.04 & 1.08 & 1.12 & 1.18 & 1.17 & 1.14 & 1.12 & 1.07 & 1.01 & 0.98 \\
\hline 30 & 0.96 & 0.99 & 1.07 & 1.11 & 1.14 & 1.20 & 1.17 & 1.14 & 1.13 & 1.08 & 1.01 & 0.98 \\
\hline 25 & 0.97 & 1.06 & 1.07 & 1.14 & 1.13 & 1.12 & 1.12 & 1.10 & 1.10 & 1.06 & 1.05 & 0.99 \\
\hline 20 & 1.02 & 1.09 & 1.13 & 1.20 & 1.14 & 1.14 & 1.11 & 1.05 & 1.06 & 1.06 & 1.05 & 1.04 \\
\hline 15 & 1.08 & 1.12 & 1.15 & 1.19 & 1.16 & 1.14 & 1.17 & 1.10 & 1.09 & 1.06 & 1.07 & 1.07 \\
\hline 10 & 1.25 & 1.27 & 1.35 & 1.42 & 1.32 & 1.28 & 1.24 & 1.17 & 1.16 & 1.16 & 1.17 & 1.23 \\
\hline 5 & 1.14 & 1.19 & 1.18 & 1.15 & 1.13 & 1.12 & 1.08 & 1.07 & 1.07 & 1.08 & 1.08 & 1.11 \\
\hline 0 & 1.07 & 1.10 & 1.08 & 1.05 & 1.04 & 1.06 & 1.06 & 1.06 & 1.07 & 1.07 & 1.06 & 1.06 \\
\hline-5 & 1.08 & 1.10 & 1.07 & 1.05 & 1.07 & 1.09 & 1.09 & 1.10 & 1.11 & 1.09 & 1.10 & 1.07 \\
\hline-10 & 1.08 & 1.09 & 1.06 & 1.06 & 1.09 & 1.12 & 1.12 & 1.16 & 1.15 & 1.14 & 1.09 & 1.08 \\
\hline-15 & 1.08 & 1.08 & 1.06 & 1.05 & 1.09 & 1.11 & 1.12 & 1.14 & 1.15 & 1.13 & 1.10 & 1.07 \\
\hline-20 & 1.16 & 1.15 & 1.12 & 1.12 & 1.11 & 1.14 & 1.13 & 1.17 & 1.23 & 1.30 & 1.26 & 1.18 \\
\hline-25 & 1.25 & 1.24 & 1.21 & 1.17 & 1.17 & 1.17 & 1.16 & 1.21 & 1.25 & 1.35 & 1.30 & 1.30 \\
\hline-30 & 1.27 & 1.23 & 1.21 & 1.19 & 1.16 & 1.13 & 1.12 & 1.16 & 1.21 & 1.28 & 1.23 & 1.30 \\
\hline-35 & 1.31 & 1.22 & 1.23 & 1.19 & 1.14 & 1.08 & 1.09 & 1.13 & 1.15 & 1.20 & 1.21 & 1.27 \\
\hline-40 & 1.22 & 1.18 & 1.18 & 1.11 & 1.10 & 1.04 & 1.04 & 1.06 & 1.07 & 1.15 & 1.17 & 1.21 \\
\hline-45 & 1.20 & 1.19 & 1.14 & 1.08 & 1.08 & 1.01 & 1.01 & 1.04 & 1.04 & 1.12 & 1.14 & 1.18 \\
\hline-50 & 1.30 & 1.22 & 1.21 & 1.09 & 1.09 & 1.04 & 1.05 & 1.08 & 1.08 & 1.14 & 1.22 & 1.22 \\
\hline-55 & 1.27 & 1.17 & 1.17 & 1.08 & 1.05 & 1.04 & 1.04 & 1.05 & 1.07 & 1.08 & 1.17 & 1.17 \\
\hline
\end{tabular}

to the conclusion that while no single $\Theta$ value gives an ideal PCT formulation applicable to all places and seasons, a range of $\Theta$ values can generally give credible results. Some readers may wish to use PCT formulations that are most appropriate for particular regions or seasons, and Tables 3-6 are suitable for selecting those $\Theta$ values. Others, including ourselves, will want to apply a single $\Theta$ value for each frequency globally, all

TABLE 5. As in Table 3, but for the 19-GHz PCT coefficient $\Theta_{19}$.

\begin{tabular}{|c|c|c|c|c|c|c|c|c|c|c|c|c|}
\hline Lat $\left(^{\circ}\right)$ & Jan & Feb & Mar & Apr & May & Jun & Jul & Aug & Sep & Oct & Nov & Dec \\
\hline 55 & 1.29 & 1.30 & 1.32 & 1.33 & 1.34 & 1.43 & 1.42 & 1.40 & 1.34 & 1.28 & 1.29 & 1.29 \\
\hline 50 & 1.28 & 1.29 & 1.34 & 1.37 & 1.39 & 1.49 & 1.44 & 1.42 & 1.38 & 1.33 & 1.32 & 1.29 \\
\hline 45 & 1.28 & 1.35 & 1.40 & 1.43 & 1.44 & 1.48 & 1.49 & 1.44 & 1.41 & 1.37 & 1.35 & 1.31 \\
\hline 40 & 1.29 & 1.34 & 1.34 & 1.36 & 1.40 & 1.45 & 1.43 & 1.40 & 1.38 & 1.35 & 1.32 & 1.29 \\
\hline 35 & 1.28 & 1.34 & 1.36 & 1.40 & 1.43 & 1.48 & 1.48 & 1.43 & 1.40 & 1.37 & 1.31 & 1.28 \\
\hline 30 & 1.23 & 1.28 & 1.36 & 1.41 & 1.42 & 1.47 & 1.42 & 1.38 & 1.38 & 1.33 & 1.26 & 1.25 \\
\hline 25 & 1.24 & 1.29 & 1.33 & 1.39 & 1.39 & 1.38 & 1.37 & 1.35 & 1.34 & 1.31 & 1.30 & 1.26 \\
\hline 20 & 1.29 & 1.37 & 1.37 & 1.42 & 1.39 & 1.38 & 1.35 & 1.29 & 1.31 & 1.31 & 1.30 & 1.31 \\
\hline 15 & 1.32 & 1.38 & 1.42 & 1.41 & 1.38 & 1.37 & 1.38 & 1.33 & 1.33 & 1.30 & 1.31 & 1.31 \\
\hline 10 & 1.62 & 1.69 & 1.74 & 1.79 & 1.57 & 1.52 & 1.48 & 1.42 & 1.41 & 1.39 & 1.39 & 1.39 \\
\hline 5 & 1.37 & 1.43 & 1.41 & 1.38 & 1.37 & 1.36 & 1.33 & 1.31 & 1.32 & 1.32 & 1.33 & 1.35 \\
\hline 0 & 1.32 & 1.34 & 1.32 & 1.30 & 1.29 & 1.31 & 1.30 & 1.31 & 1.32 & 1.31 & 1.31 & 1.31 \\
\hline-5 & 1.33 & 1.35 & 1.32 & 1.30 & 1.32 & 1.33 & 1.33 & 1.34 & 1.35 & 1.34 & 1.34 & 1.32 \\
\hline-10 & 1.32 & 1.33 & 1.31 & 1.30 & 1.33 & 1.35 & 1.36 & 1.39 & 1.39 & 1.37 & 1.34 & 1.32 \\
\hline-15 & 1.33 & 1.33 & 1.31 & 1.30 & 1.33 & 1.35 & 1.37 & 1.40 & 1.41 & 1.39 & 1.35 & 1.32 \\
\hline-20 & 1.42 & 1.39 & 1.38 & 1.37 & 1.35 & 1.41 & 1.43 & 1.46 & 1.59 & 1.63 & 1.58 & 1.46 \\
\hline-25 & 1.53 & 1.48 & 1.48 & 1.44 & 1.46 & 1.49 & 1.51 & 1.56 & 1.59 & 1.70 & 1.68 & 1.59 \\
\hline-30 & 1.49 & 1.47 & 1.44 & 1.42 & 1.40 & 1.40 & 1.43 & 1.42 & 1.47 & 1.59 & 1.48 & 1.51 \\
\hline-35 & 1.57 & 1.47 & 1.49 & 1.46 & 1.42 & 1.39 & 1.41 & 1.43 & 1.44 & 1.51 & 1.49 & 1.58 \\
\hline-40 & 1.48 & 1.44 & 1.44 & 1.39 & 1.40 & 1.34 & 1.35 & 1.38 & 1.38 & 1.45 & 1.47 & 1.49 \\
\hline-45 & 1.67 & 1.66 & 1.59 & 1.38 & 1.49 & 1.39 & 1.39 & 1.45 & 1.41 & 1.49 & 1.56 & 1.68 \\
\hline-50 & 1.79 & 1.75 & 1.72 & 1.55 & 1.53 & 1.49 & 1.51 & 1.53 & 1.53 & 1.61 & 1.73 & 1.75 \\
\hline-55 & 1.66 & 1.59 & 1.57 & 1.47 & 1.43 & 1.43 & 1.44 & 1.45 & 1.43 & 1.48 & 1.55 & 1.59 \\
\hline
\end{tabular}


TABLE 6. As in Table 3, but for the 10-GHz PCT coefficient $\Theta_{10}$.

\begin{tabular}{|c|c|c|c|c|c|c|c|c|c|c|c|c|}
\hline Lat $\left(^{\circ}\right)$ & Jan & Feb & Mar & Apr & May & Jun & Jul & Aug & Sep & Oct & Nov & Dec \\
\hline 55 & 1.47 & 1.50 & 1.53 & 1.53 & 1.53 & 1.61 & 1.58 & 1.55 & 1.49 & 1.45 & 1.47 & 1.48 \\
\hline 50 & 1.47 & 1.50 & 1.55 & 1.54 & 1.54 & 1.65 & 1.58 & 1.55 & 1.52 & 1.49 & 1.48 & 1.47 \\
\hline 45 & 1.44 & 1.49 & 1.73 & 1.79 & 1.58 & 1.63 & 1.63 & 1.57 & 1.55 & 1.53 & 1.49 & 1.47 \\
\hline 40 & 1.48 & 1.54 & 1.56 & 1.57 & 1.58 & 1.62 & 1.58 & 1.53 & 1.52 & 1.51 & 1.49 & 1.48 \\
\hline 35 & 1.45 & 1.53 & 1.57 & 1.60 & 1.61 & 1.63 & 1.62 & 1.51 & 1.50 & 1.52 & 1.46 & 1.46 \\
\hline 30 & 1.36 & 1.40 & 1.50 & 1.55 & 1.55 & 1.57 & 1.52 & 1.48 & 1.48 & 1.44 & 1.38 & 1.37 \\
\hline 25 & 1.36 & 1.41 & 1.46 & 1.49 & 1.50 & 1.50 & 1.47 & 1.45 & 1.44 & 1.42 & 1.38 & 1.37 \\
\hline 20 & 1.40 & 1.47 & 1.47 & 1.51 & 1.50 & 1.47 & 1.45 & 1.40 & 1.42 & 1.42 & 1.42 & 1.43 \\
\hline 15 & 1.42 & 1.47 & 1.50 & 1.49 & 1.48 & 1.47 & 1.46 & 1.43 & 1.43 & 1.41 & 1.41 & 1.42 \\
\hline 10 & 1.79 & 1.79 & 1.79 & 1.78 & 1.68 & 1.64 & 1.58 & 1.53 & 1.51 & 1.48 & 1.48 & 1.79 \\
\hline 5 & 1.46 & 1.50 & 1.49 & 1.46 & 1.46 & 1.45 & 1.43 & 1.42 & 1.43 & 1.42 & 1.43 & 1.43 \\
\hline 0 & 1.42 & 1.44 & 1.43 & 1.42 & 1.41 & 1.42 & 1.40 & 1.41 & 1.42 & 1.42 & 1.42 & 1.41 \\
\hline-5 & 1.43 & 1.45 & 1.42 & 1.41 & 1.42 & 1.43 & 1.43 & 1.44 & 1.45 & 1.44 & 1.45 & 1.43 \\
\hline-10 & 1.43 & 1.44 & 1.42 & 1.40 & 1.43 & 1.45 & 1.45 & 1.49 & 1.49 & 1.47 & 1.44 & 1.43 \\
\hline-15 & 1.44 & 1.44 & 1.42 & 1.41 & 1.43 & 1.45 & 1.50 & 1.51 & 1.52 & 1.49 & 1.46 & 1.43 \\
\hline-20 & 1.54 & 1.50 & 1.49 & 1.47 & 1.45 & 1.57 & 1.59 & 1.66 & 1.75 & 1.79 & 1.79 & 1.61 \\
\hline-25 & 1.64 & 1.57 & 1.61 & 1.55 & 1.67 & 1.71 & 1.73 & 1.78 & 1.79 & 1.79 & 1.79 & 1.79 \\
\hline-30 & 1.59 & 1.56 & 1.54 & 1.53 & 1.51 & 1.51 & 1.58 & 1.56 & 1.60 & 1.73 & 1.61 & 1.62 \\
\hline-35 & 1.69 & 1.58 & 1.62 & 1.58 & 1.58 & 1.55 & 1.57 & 1.59 & 1.61 & 1.71 & 1.66 & 1.72 \\
\hline-40 & 1.62 & 1.57 & 1.55 & 1.52 & 1.55 & 1.50 & 1.52 & 1.59 & 1.54 & 1.59 & 1.61 & 1.61 \\
\hline-45 & 1.56 & 1.53 & 1.53 & 1.79 & 1.79 & 1.76 & 1.77 & 1.79 & 1.79 & 1.79 & 1.53 & 1.53 \\
\hline-50 & 1.62 & 1.56 & 1.59 & 1.79 & 1.79 & 1.79 & 1.79 & 1.79 & 1.79 & 1.79 & 1.58 & 1.59 \\
\hline-55 & 1.79 & 1.79 & 1.79 & 1.79 & 1.79 & 1.77 & 1.79 & 1.78 & 1.76 & 1.79 & 1.79 & 1.79 \\
\hline
\end{tabular}

through the year. The most straightforward choice and seasons. Our recommendations (Table 7) also round would be to take the $\Theta$ values highlighted in section $3 \mathrm{a}$, the $\Theta$ values to the nearest 0.05 , since Figs. $2-4$ and the but instead we recommend some slight modifications to analysis by latitude and by month suggest that precision account for varying performance in different regions to the nearest 0.01 is not warranted.

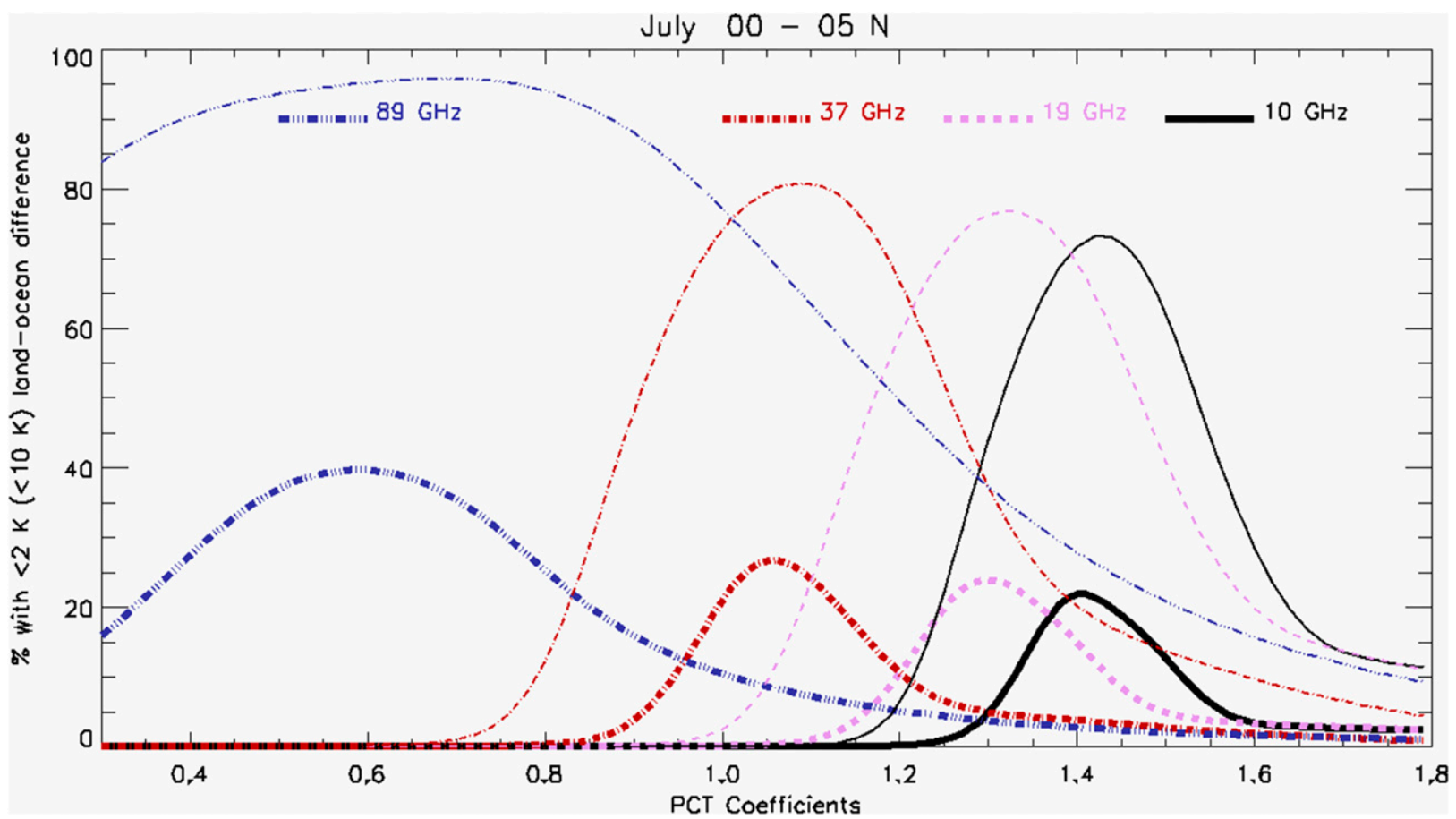

FIG. 5. Percentage of land-water PCT differences less than $2 \mathrm{~K}$ (thick lines) and less than $10 \mathrm{~K}$ (thin lines), as a function of $\Theta$ value, for the $0^{\circ}-5^{\circ} \mathrm{N}$ latitude bin during July. 


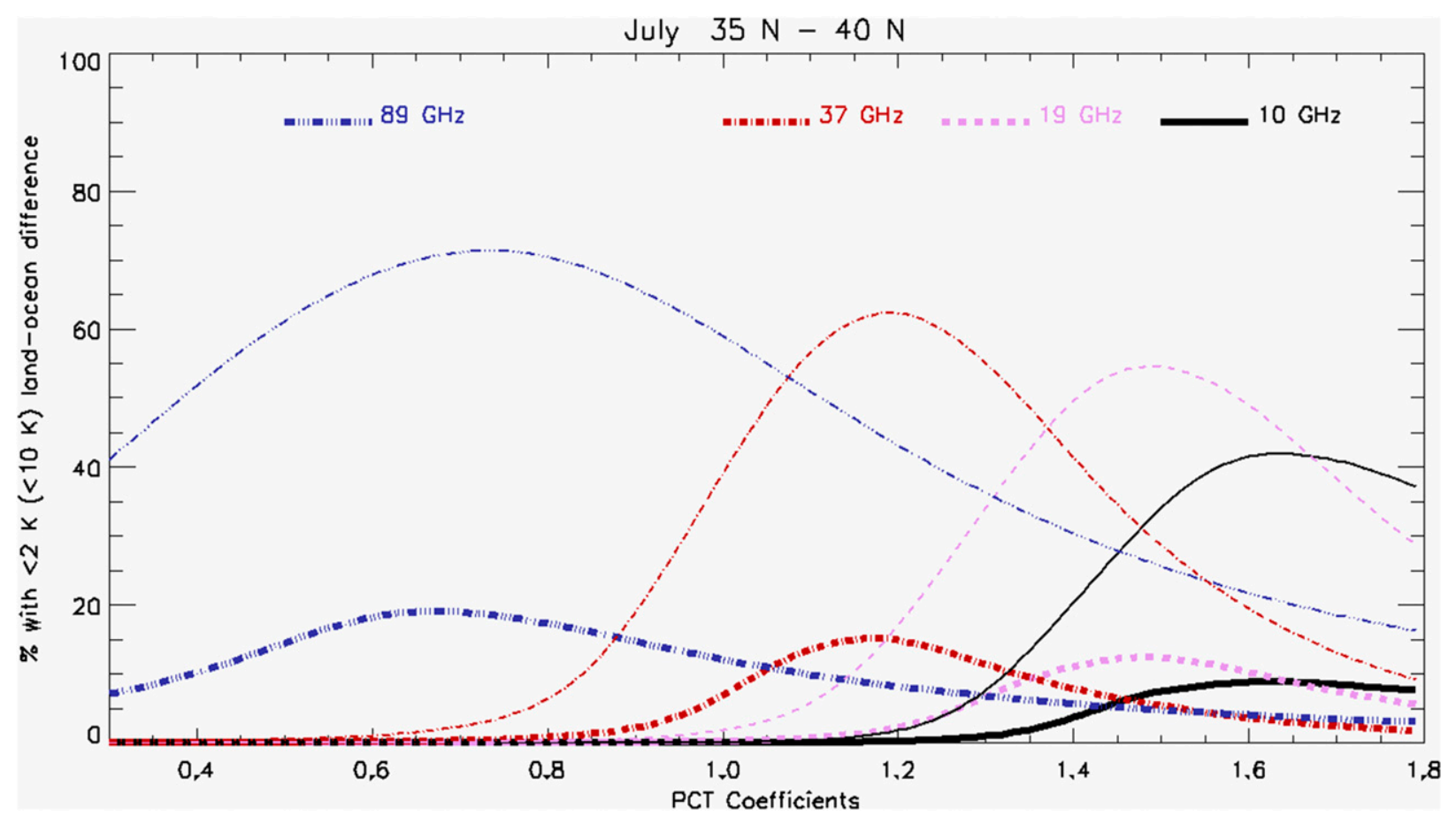

FIG. 6. As in Fig. 5, but for the $35^{\circ}-40^{\circ} \mathrm{N}$ latitude bin.

The result that a high degree of precision is not warranted in selecting $\Theta$ values also suggests that the same coefficients should be appropriate for use with other passive microwave sensors, despite differences in footprint sizes or radiometer frequencies. Small variations in the frequencies used by different radiometers can lead to brightness temperature differences of a few kelvins in rain-free regions (or several kelvins in rain, but raining pixels are omitted from the computation of PCT coefficients) (Yang et al. 2014). If the entire analysis were repeated using an $85.5-\mathrm{GHz}$ (e.g., SSM/I or TMI) or $91.7-\mathrm{GHz}$ (e.g., SSM/I/Sounder) frequency instead of the GMI's 89.0-GHz frequency, there might be small changes in the details in section 3 , but likely no significant change in the choice of $\Theta$. Likewise, differences in the sensors' footprint sizes should have little effect, especially since the analysis is done using precipitation-free pixels.

For passive microwave channels in the range $85-92 \mathrm{GHz}$ (including SSM/I, TMI, GMI, and AMSR), we recommend $\Theta_{89}=0.70$. This tends more toward the higher values that work well in the midlatitude warm seasons than the lower values that work best in the tropics, since performance of $\mathrm{PCT}_{89}$ in the tropics is less sensitive to the precise choice of $\Theta_{89}$. For similar reasons, we recommend $\Theta_{37}=1.15$ for the $36-37-\mathrm{GHz}$ channels on SSM/I, TMI, GMI, and AMSR.

Many publications have used $\Theta_{85}=0.818$ and $\Theta_{37}=1.2$ for PCT based on Spencer et al. (1989) and Toracinta et al. (2002), particularly for studies involving TRMM

TABLE 7. The PCT coefficients $\Theta$ from this study and from the literature.

\begin{tabular}{llcc}
\hline \hline \multicolumn{1}{c}{ Source } & \multicolumn{1}{c}{$85-89 \mathrm{GHz}$} & $36-37 \mathrm{GHz}$ & $19 \mathrm{GHz}$ \\
\hline This study & $0.70(\mathrm{GMI})$ & $1.15(\mathrm{GMI})$ & $1.40(\mathrm{GMI})$ \\
Spencer et al. (1989) & $0.818(\mathrm{SSM} / \mathrm{I})$ & & \\
& $0.54-0.61$ (model) & $1.50(\mathrm{GMI})$ \\
Toracinta et al. (2002) & & 1.20 (TMI) & \\
Weinman and Guetter (1977) & & 1.50 (ESMR) & \\
& & 1.08 (SMMR) & 1.38 (SMMR) \\
Grody (1984) & $0.64(\mathrm{SSM} / \mathrm{I})$ & & \\
Barrett and Kidd (1990) & & 1.18 & \\
Todd and Bailey (1995); Kidd (1998) & $0.5-0.75(\mathrm{SSM} / \mathrm{I})$ & & \\
Lee et al. (2002) & & & \\
\hline
\end{tabular}




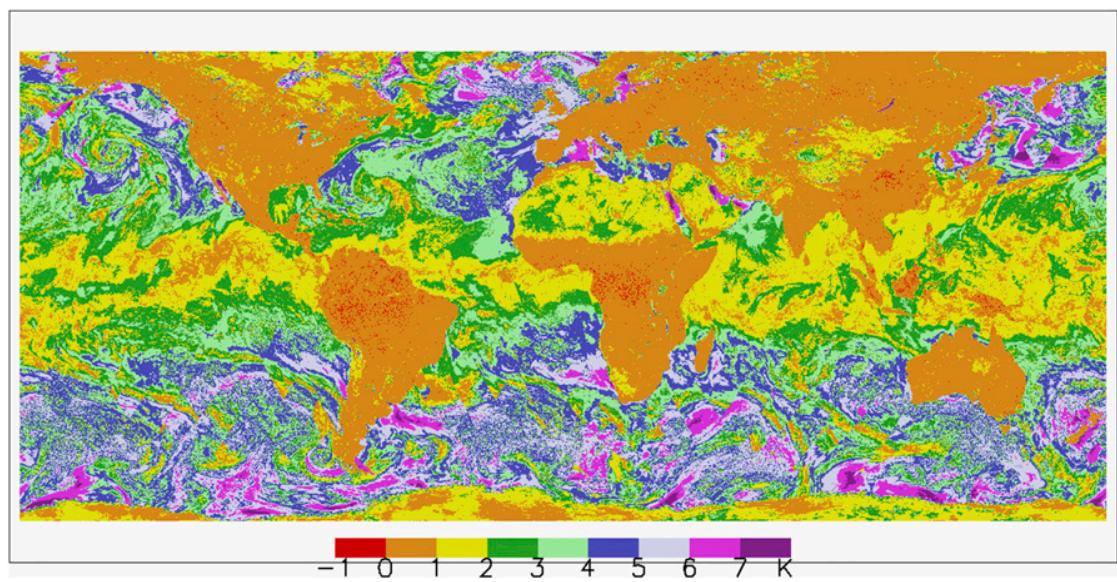

FIG. 7. Difference between $\mathrm{PCT}_{89}$ computed using $\Theta_{85}=0.818$ (Spencer et al. 1989) minus that using $\Theta_{89}=0.70$ (from this study). Three days of GPM orbits (26-28 May 2015) are mapped.

and GPM precipitation feature databases (Nesbitt et al. 2000; Liu et al. 2008). Figures 7 and 8 compare PCT values computed using our recommended $\Theta$ values to those computed using the Spencer et al. (1989) and Toracinta et al. (2002) values. The differences are mostly small, which was expected because the Spencer et al. and Toracinta et al. versions have both proven effective over the years. Figures 2 and 4 show that these small changes do tend to slightly reduce the land-water contrasts when using our new versions of $\mathrm{PCT}_{89}$ and $\mathrm{PCT}_{37}$. Since the PCT formula in Eq. (1) can be rearranged to include a term with $\Theta$ multiplying the polarization difference, our lower choices of $\Theta$ almost always lead to slightly lower PCT values. The choice of $\Theta$ has least effect where polarization differences are small (e.g., most land areas) and greatest effect where polarization differences are large (e.g., water surfaces beneath optically thin air masses). For $\mathrm{PCT}_{89}$, the differences are less than $1 \mathrm{~K}$ over most land areas and 1-4 K over most ocean locations. Exceptions over land are deserts and areas of snow or ice cover, where $\mathrm{PCT}_{89}$ tends to be $1-3 \mathrm{~K}$ lower using our choice of $\Theta_{89}$. Over oceans, the largest differences (4-8 K) coincide with dry air masses, particularly at midand high latitudes. For $\mathrm{PCT}_{37}$, the differences over land are again less than $1 \mathrm{~K}$ except for deserts and snowpacks, where the differences are 1-2 K. Over oceans, the differences are only $2-4 \mathrm{~K}$, with the higher values coinciding with drier air masses. For both frequencies, the differences are only a few tenths of a kelvin for pixels with substantial precipitation signatures.

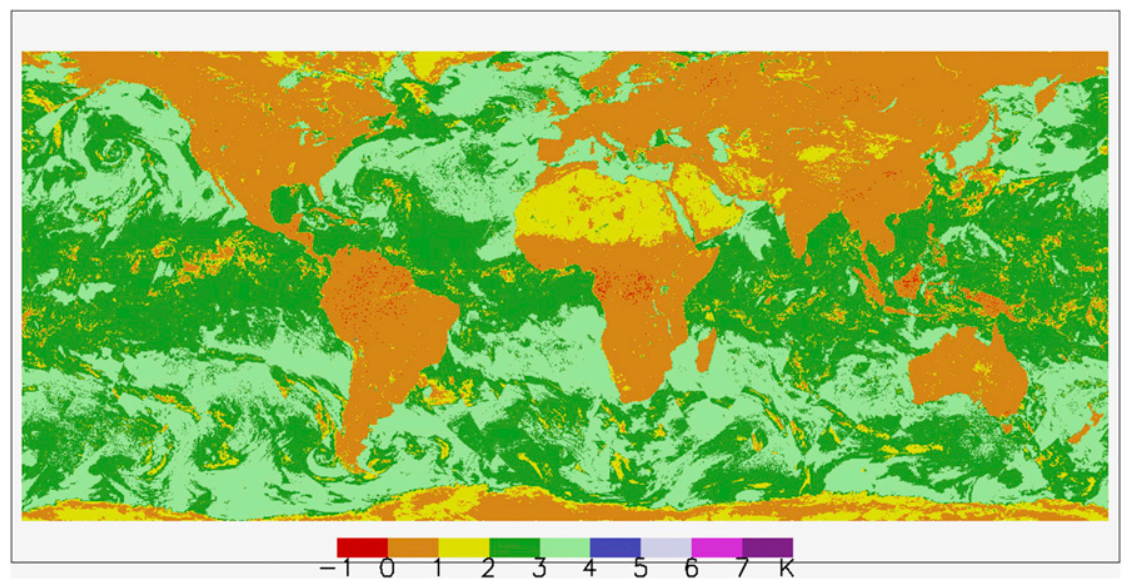

FIG. 8. Difference between $\mathrm{PCT}_{37}$ computed using $\Theta_{37}=1.20$ (Toracinta et al. 2002) minus that using $\Theta_{37}=1.15$ (from this study). Three days of GPM orbits (26-28 May 2015) are mapped. 


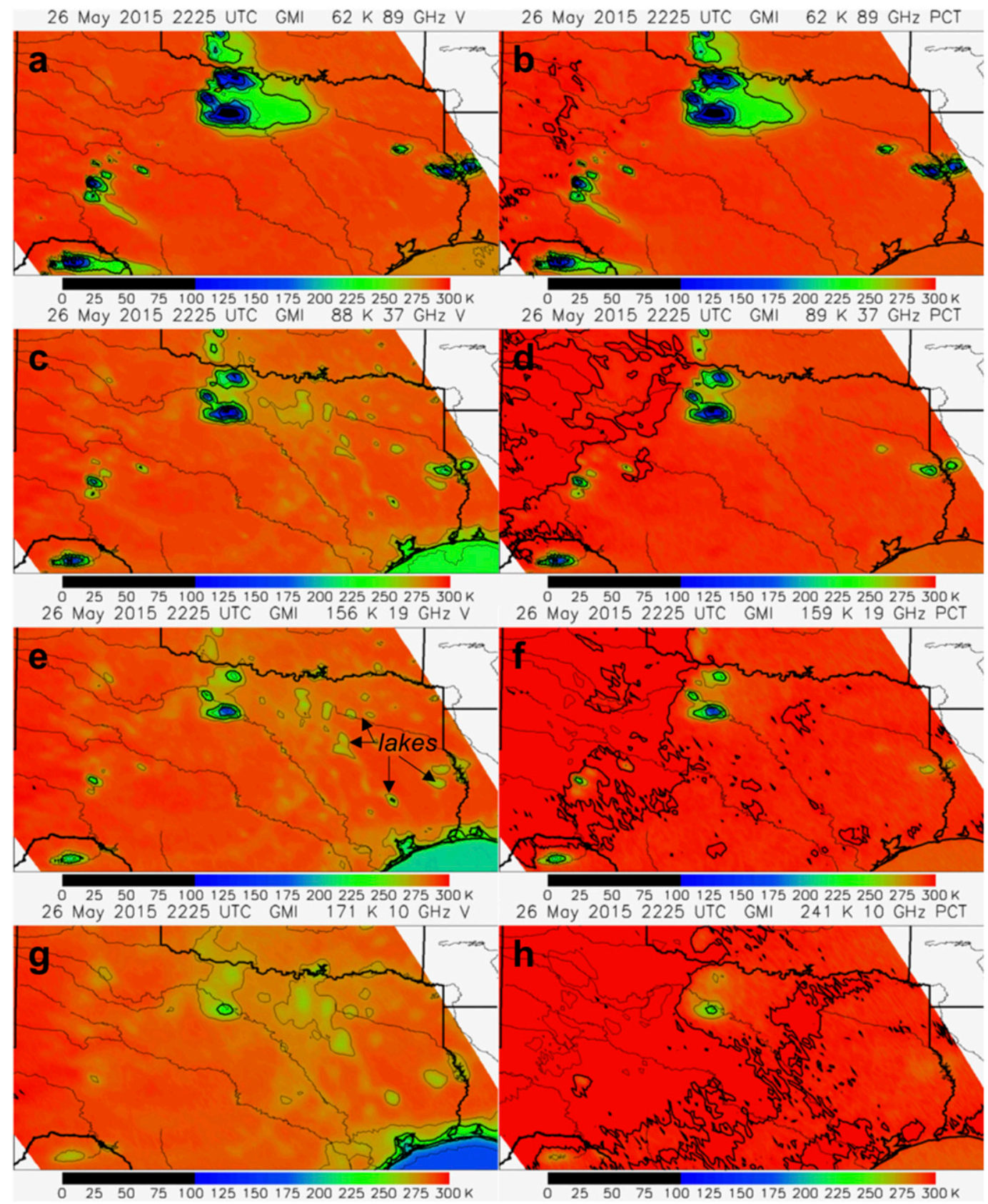

FIG. 9. GMI case from west of Fort Worth on 26 May 2015: (left) vertically polarized brightness temperature and (right) PCT. Contour interval is $25 \mathrm{~K}$, with thick contours every $50 \mathrm{~K}$. The minimum brightness temperature (or PCT) of the domain is printed.

For $19-\mathrm{GHz}$ channels (including SSM/I, TMI, GMI, and AMSR), we recommend $\Theta_{19}=1.40$. This is essentially the same (after rounding) as the 1.38 value used by Grody (1984), with which we were not familiar until preparing this manuscript. For channels near $10 \mathrm{GHz}$ (TMI, GMI, and AMSR), we recommend $\Theta_{10}=1.50$. As with the higher-frequency channels, these recommendations for the lower-frequency channels are compromises that are intended to work best in both the tropics and during midlatitude warm seasons. For the lower-frequency channels, the ability to eliminate differences between land and water-covered scenes is substantially reduced compared to the higher-frequency channels.

We briefly consider cases with intense convective storms that were observed by GMI, TMI, AMSR-E, and 

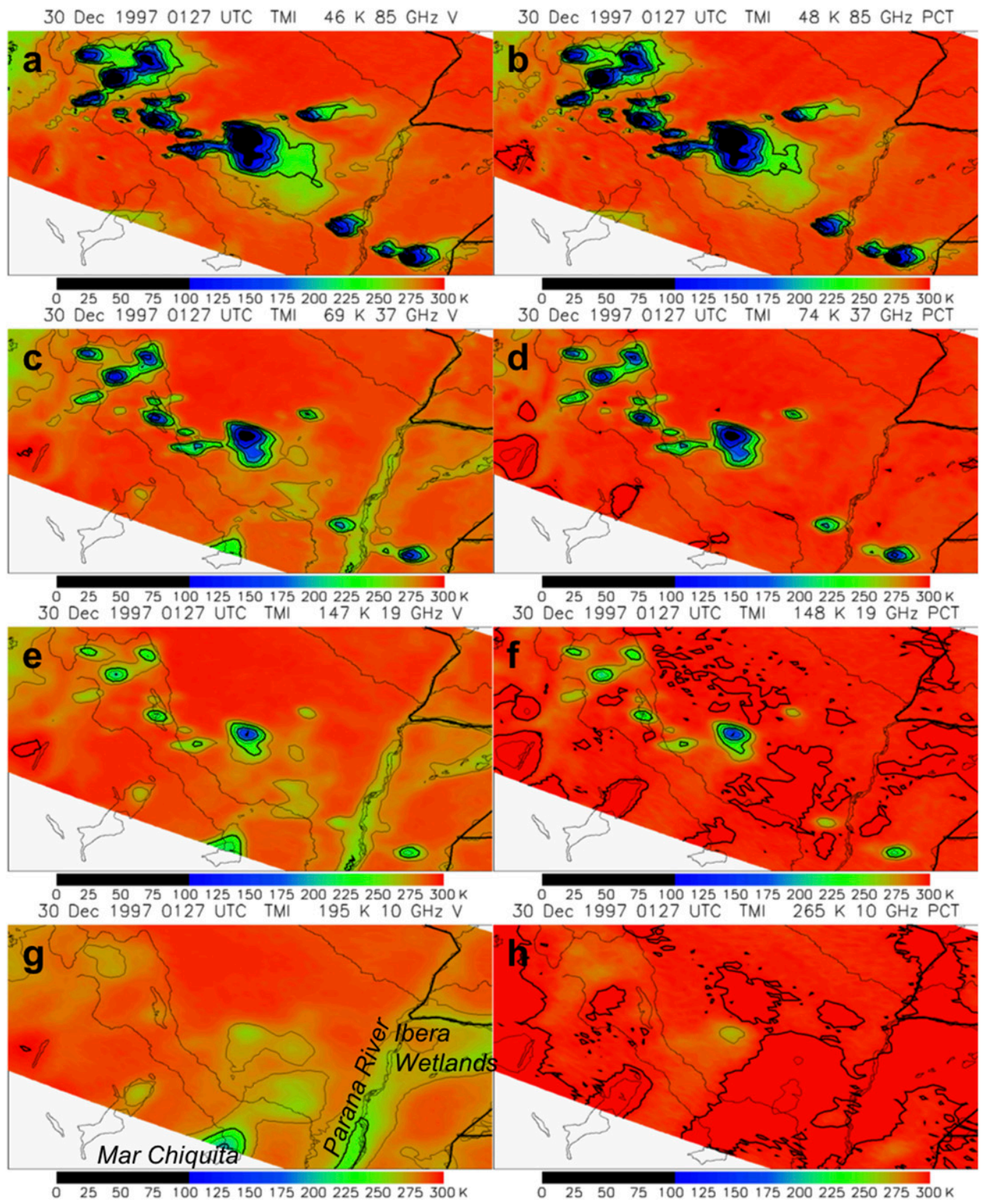

FIG. 10. As in Fig. 9, but for a TMI case from northern Argentina on 30 Dec 1997. (a),(b) The TB $85 \mathrm{~V}$ and $\mathrm{PCT}_{85}$ were rederived with X-CAL offsets applied to level 1B files, because the level 1C X-CAL files have values below $50 \mathrm{~K}$ set as missing.

$\mathrm{SSM} / \mathrm{I}$, in order to demonstrate the utility of these new PCT formulations. These cases were previously identified by Cecil (2015) as having some of the most extreme 37- or $89-\mathrm{GHz}$ scattering signatures for those satellites. For each example in Figs. 9-12, the left panels show vertically polarized brightness temperatures and the right panels show PCT (using our recommended coefficients, as in Table 7).
The storms around Texas shown in Fig. 1 are revisited in Fig. 9, a case observed by GMI on 26 May 2015. At $89 \mathrm{GHz}$ (Figs. 9a,b), the effect of the PCT is not especially noticeable for this case, other than bringing the Gulf of Mexico temperatures closer to those over land. For the 37-, 19-, and 10-GHz frequencies, the PCT eliminates the sharp gradient at the coast and also eliminates the signatures associated with lakes that were 

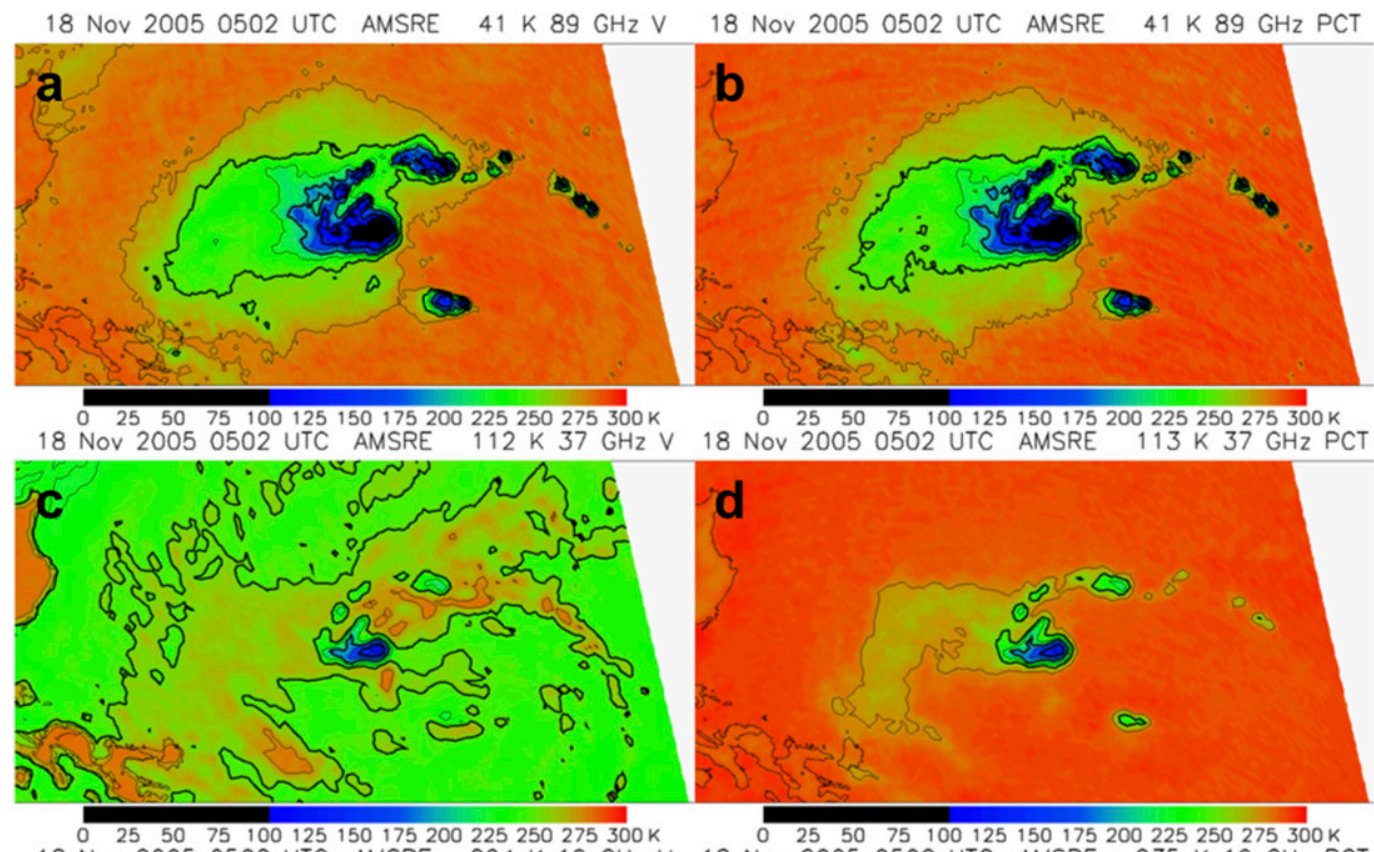

18 Nov 20050502 UTC AMSRE $204 \mathrm{~K} 19 \mathrm{GHz}$ V
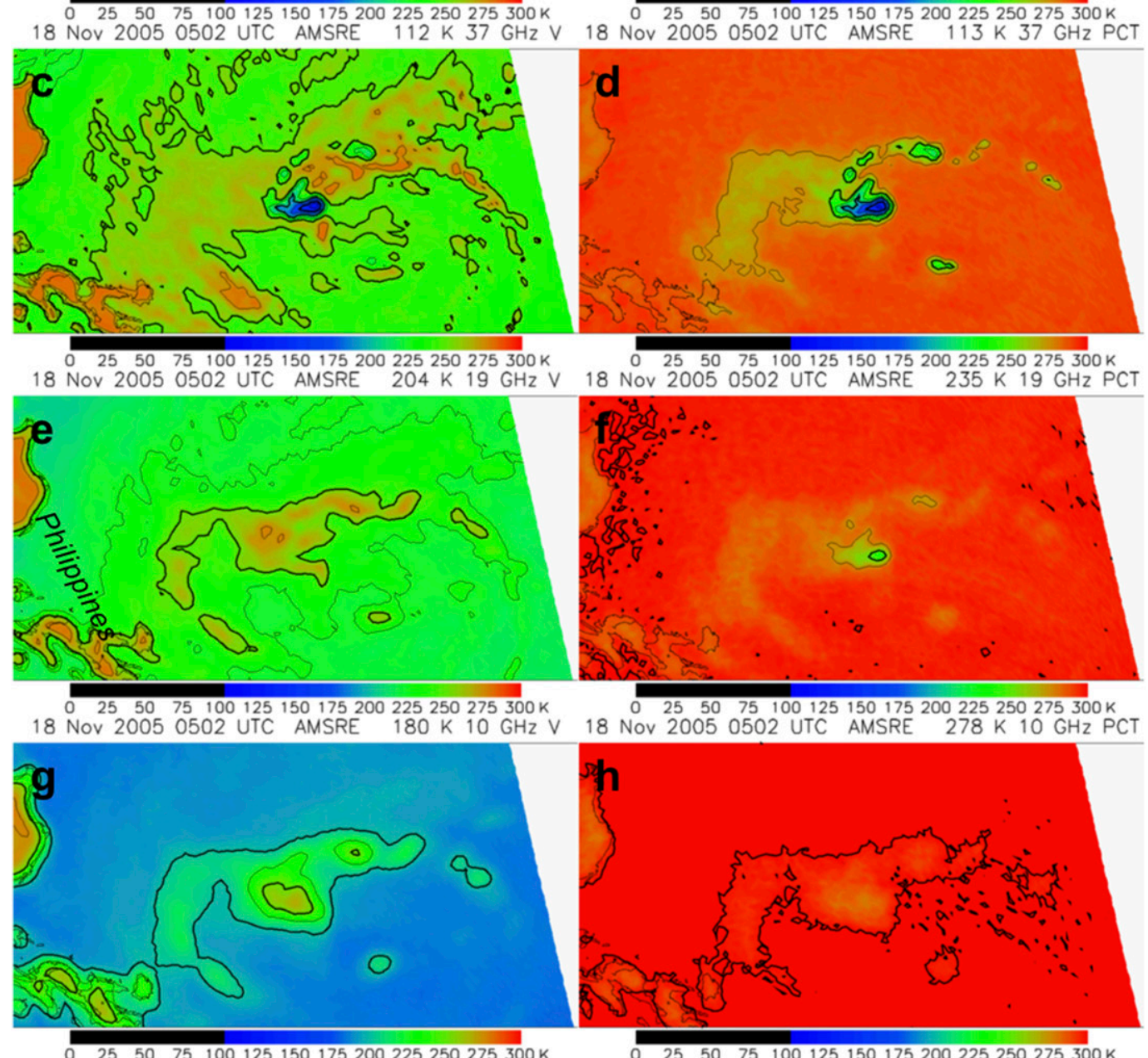

FIG. 11. As in Fig. 9, but for AMSR-E case of Typhoon Bolaven east of the Philippines on 18 Nov 2005. (a),(b) The $\mathrm{TB}_{89 \mathrm{~V}}$ and $\mathrm{PCT}_{89}$ were taken from AMSR-E level 2A brightness temperatures distributed by NSIDC, because the level $1 \mathrm{CX}$-CAL files have values below $50 \mathrm{~K}$ set as missing. Comparison of nearby pixels slightly above $50 \mathrm{~K}$ suggests the calibrations are consistent within $1.0 \mathrm{~K}$.

mentioned in Fig. 1. The individual figure panels identify the minimum brightness temperature (or PCT) for each panel. Most of these minima are associated with the strongest storm, west of Fort Worth, Texas. The minimum $\mathrm{TB}_{10 \mathrm{~V}}$ (Fig. 9g) is a precipitation-free Gulf of Mexico scene, but $\mathrm{PCT}_{10}$ (Fig. 9h) is minimized over the storm, as desired.

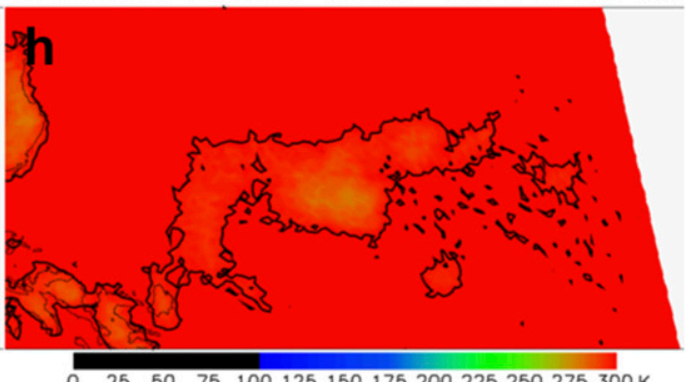

$0 \begin{array}{llllllll}25 & 50 & 75 & 100125150175200225250275300 \mathrm{~K}\end{array}$ 

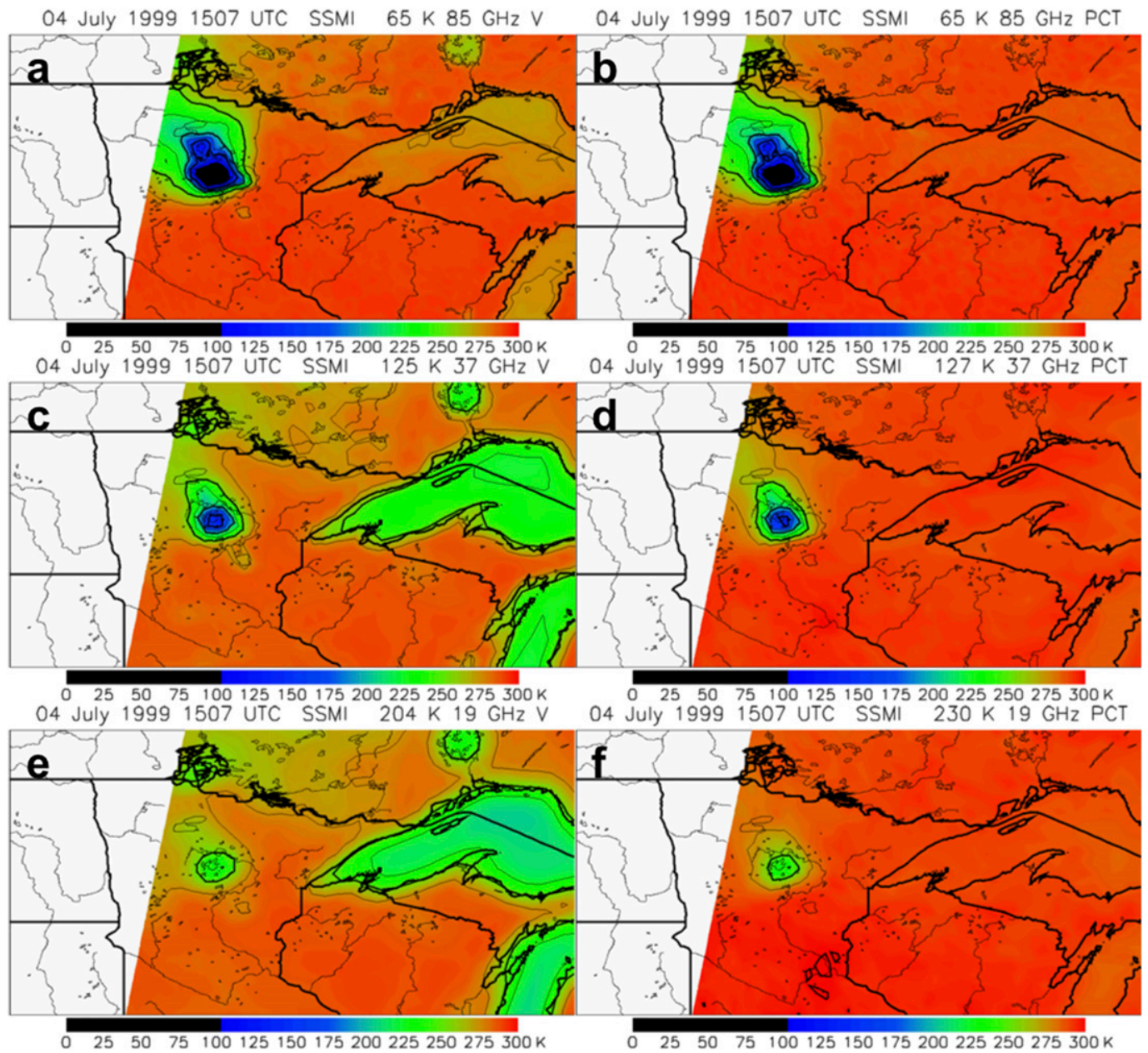

FIG. 12. As in Fig. 9, but for an SSM/I case from Minnesota on 4 Jul 1999.

and mentioned its lowest $\mathrm{PCT}_{37}$ as $69 \mathrm{~K}$. Its minimum $\mathrm{PCT}_{37}$ is higher $(74 \mathrm{~K})$ in Fig. 10d because of two calibrations that were applied to TMI since that paper. The update from TRMM version 7 to version 8 (now known as GPM version 5, because TRMM is treated as part of the GPM constellation) increased $\mathrm{TB}_{37 \mathrm{~V}}$ and $\mathrm{TB}_{37 \mathrm{H}}$ by 2.8 and $2.5 \mathrm{~K}$, respectively, for the coldest pixel in this case. The recalibration for consistency with GMI (known as the GPM X-CAL level 1C brightness temperatures) increases $\mathrm{TB}_{37 \mathrm{~V}}$ by $0.69 \mathrm{~K}$ and decreases $\mathrm{TB}_{37 \mathrm{H}}$ by $1.56 \mathrm{~K}$ for the low end of $\mathrm{TB}_{37}$ values, such as this. The increased $\mathrm{TB}_{37 \mathrm{~V}}-\mathrm{TB}_{37 \mathrm{H}}$ polarization difference adds to the $\mathrm{PCT}_{37}$. The change from using Toracinta et al.'s (2002) $\Theta_{37}$ coefficient [also used by Zipser et al. (2006)] to ours only amounts to a $0.3-\mathrm{K}$ difference between the two formulations.

Typhoon Bolaven (2005) is shown in Fig. 11, as observed near the Philippines (east of Luzon) by AMSR-E on 18 November 2005. The use of PCT again eliminates most of the land-water contrast (with the Philippines on the far left of each panel). But the PCT also removes much of the signal from rain in the lower-frequency channels. Emission by liquid rain is seen as warm brightness temperatures over ocean in the left panels, but only the scattering by large ice particles is highlighted by the PCT in the right panels.

The SSM/I has coarser resolution than GMI, TMI, and AMSR-E, and lacks a $10-\mathrm{GHz}$ channel, but the PCT highlights intense convection in SSM/I's 19-, 37-, and 85-GHz frequencies. The "Boundary Waters Derecho" (Price and Murphy 2002) case (Fig. 12) featured an intense storm in northern Minnesota. The PCT is again effective at removing the signal associated with the lakes in this region and drawing attention to the storm.

The cases shown in Figs. 9-12 were selected because they were known to have extremely low $\mathrm{PCT}_{37}$ values, so they were good candidates for having substantial ice scattering signatures in the $19-$ and $10-\mathrm{GHz}$ channels. Indeed, the GMI and TMI cases had $\mathrm{PCT}_{19}$ reduced from near $300 \mathrm{~K}$ in the surrounding areas to 159 and 
$149 \mathrm{~K}$, respectively, at the convective cores. Those two cases also had noticeable scattering signatures in $\mathrm{PCT}_{10}$ ( 241 and $265 \mathrm{~K}$, respectively), despite the longer wavelength and coarser resolution for this frequency (Table 2). The AMSR-E case (Typhoon Bolaven; Fig. 11) had weaker signatures in the low-frequency channels $(235-\mathrm{K}$ $\left.\mathrm{PCT}_{19} ; 278-\mathrm{K} \mathrm{PCT}_{10}\right)$ than the GMI and TMI cases, but it also had a weaker signature at $37 \mathrm{GHz}(113 \mathrm{~K})$. It had the lowest $\mathrm{TB}_{\mathrm{V} 89}(41 \mathrm{~K})$ and $\mathrm{PCT}_{89}(41 \mathrm{~K})$ values of all these cases, which may result from having an extraordinarily deep vertical layer of large graupel. The SSM/I case from Minnesota had $\mathrm{PCT}_{19}$ reduced to $230 \mathrm{~K}$, despite SSM/I's coarse resolution. Another SSM/I case from the same region (28 June 1998) had $\mathrm{PCT}_{19}$ scattered to $217 \mathrm{~K}$ (not shown).

\section{Conclusions}

Coefficients have been derived for computing PCT for 10-, 19-, 37- and 89-GHz (and similar) frequencies from GMI and related radiometers. While coefficient values can be optimized for particular regions and seasons using Tables 3-6, we recommend the values listed in Table 7 for global applications. These result in the following formulas:

$$
\begin{aligned}
& \mathrm{PCT}_{10}=2.5 \mathrm{~TB}_{10 \mathrm{~V}}-1.5 \mathrm{~TB}_{10 \mathrm{H}}, \\
& \mathrm{PCT}_{19}=2.4 \mathrm{~TB}_{19 \mathrm{~V}}-1.4 \mathrm{~TB}_{19 \mathrm{H}}, \\
& \mathrm{PCT}_{37}=2.15 \mathrm{~TB}_{37 \mathrm{~V}}-1.15 \mathrm{~TB}_{37 \mathrm{H}}, \quad \text { and } \\
& \mathrm{PCT}_{89}=1.7 \mathrm{~TB}_{89 \mathrm{~V}}-0.7 \mathrm{~TB}_{89 \mathrm{H}} .
\end{aligned}
$$

These values were tested using four cases with intense convection observed separately by the GMI, TMI, AMSR-E, and SSM/I sensors. The new PCT formulations eliminated much of the contrast between land and water surfaces in all four cases and for all four frequencies. The intense convection is easily recognized with PCT depressions in each case, without having surface-related characteristics contributing other ambiguous PCT depressions.

Other formulations of $\mathrm{PCT}_{89}$ and $\mathrm{PCT}_{37}$ have become well established. Differences between our $\mathrm{PCT}_{89}$ and that from Spencer et al. (1989) and between our $\mathrm{PCT}_{37}$ and that from Toracinta et al. (2002) were examined and tend to be small, especially for measurements involving ice scattering related to precipitation. Otherwise, our $\mathrm{PCT}_{89}$ and $\mathrm{PCT}_{37}$ tend to be a few kelvins lower than the previous formulations over the oceans. The largest differences are over relatively dry oceanic air masses. Differences over land are usually less than $1 \mathrm{~K}$, except for deserts and snow- or ice-covered regions.
The key new developments from this paper are the coefficients for computing $\mathrm{PCT}_{19}$ and $\mathrm{PCT}_{10}$. We see these as tools for further investigating intense thunderstorms, using GPM and other satellites with related sensors. Indeed, Mroz et al. (2017) obtained higher skill scores for hail detection using a preliminary version of our $\mathrm{PCT}_{19}$ than the scores obtained using higher frequencies or individual polarizations. Here, $\mathrm{PCT}_{19}$ and $\mathrm{PCT}_{10}$ essentially mask the signals that come from inland water bodies or from coasts. They also have little sensitivity to most precipitation, but help draw attention to the most intense convection, capable of producing large amounts of hail and/or graupel that scatter the upwelling radiation in these frequencies.

Acknowledgments. This research is supported by NASA's Precipitation Measurement Mission Science Team (NNH15ZDA001N-PMM). GPM data provided by the National Aeronautics and Space Administration (NASA) and the Japan Aerospace Exploration Agency (JAXA) through the Precipitation Processing System website (http://pps.gsfc.nasa.gov/).

\section{REFERENCES}

Ashcroft, P., and F. J. Wentz, 2013. AMSR-E/Aqua L2A Global Swath Spatially-Resampled Brightness Temperatures, Version 3. Distributed Active Archive Center, NASA National Snow and Ice Data Center, accessed 18 June 2013, https:// dx.doi.org/10.5067/AMSR-E/AE_L2A.003.

Barrett, E. C., and C. Kidd, 1990: Rainfall monitoring by the SSM/I in middle latitudes. Fifth Conf. on Satellite Meteorology and Oceanography, London, United Kingdom, Amer. Meteor. Soc., 210-214.

Berg, W., and Coauthors, 2016: Intercalibration of the GPM microwave radiometer constellation. J. Atmos. Oceanic Technol., 33, 2639-2654, https://doi.org/10.1175/JTECH-D-16-0100.1.

Cecil, D. J., 2009: Passive microwave brightness temperatures as proxies for hailstorms. J. Appl. Meteor. Climatol., 48, 1281-1286, https://doi.org/10.1175/2009JAMC2125.1.

_ 2015: Extremely low passive microwave brightness temperatures due to thunderstorms. 20th Conf. on Satellite Meteorology and Oceanography, Phoenix, AZ, Amer. Meteor. Soc., J13.1A, https://ams.confex.com/ams/95Annual/webprogram/ Paper266429.html.

__ , and C. B. Blankenship, 2012: Toward a global climatology of severe hailstorms as estimated by satellite passive microwave imagers. J. Climate, 25, 687-703, https://doi.org/10.1175/JCLI-D-11-00130.1.

— S. J. Goodman, D. J. Boccippio, E. J. Zipser, and S. W. Nesbitt, 2005: Three years of TRMM precipitation features. Part I: Radar, radiometric, and lightning characteristics. Mon. Wea. Rev., 133, 543-566, https://doi.org/10.1175/MWR-2876.1.

GES DISC, 2016: GPM_1BGMI: GPM GMI brightness temperatures L1B 1.5 hours $13 \mathrm{~km}$ V05. Goddard Earth Sciences Data and Information Services Center, accessed 24 May 2017, https://doi.org/10.5067/GPM/GMI/GPM/1B/05.

_ 2 2017a: GPM_1CTRMMTMI: GPM TMI on TRMM common calibrated brightness temperatures L1C 1.5 hours 
$13 \mathrm{~km}$ V05. Goddard Earth Sciences Data and Information Services Center, accessed 28 December 2017, https://doi.org/ 10.5067/GPM/TMI/TRMM/1C/05.

——, 2017b: GPM_1CAQUAAMSRE: GPM AMSR-E on AQUA common calibrated brightness temperatures L1C 1.5 hours $10.5 \mathrm{~km}$ V05. Goddard Earth Sciences Data and Information Services Center, accessed 28 December 2017, https://doi.org/10.5067/GPM/AMSRE/AQUA/1C/05.

- $2017 \mathrm{c}$ : GPM SSMI on F14 common calibrated brightness temperatures L1C 1.5 hours $13 \mathrm{~km} \mathrm{V05.} \mathrm{Goddard} \mathrm{Earth}$ Sciences Data and Information Services Center, accessed 28 December 2017, https://doi.org/10.5067/GPM/SSMI/F14/1C/05. _ 2017d: GPM_1BTMI: GPM TMI on TRMM brightness temperatures L1B 1.5 hours $13 \mathrm{~km} \mathrm{V05.} \mathrm{Goddard} \mathrm{Earth}$ Sciences Data and Information Services Center, accessed 28 December 2017, https://doi.org/10.5067/GPM/TMI/TRMM/1B/05.

Grody, N. C., 1984: Precipitation monitoring over land from satellites by microwave radiometry. Proc. Int. Geosciences and Remote Sensing Symp., Strasbourg, France, ESA SP-215, 417-423.

Hollinger, J. P., J. L. Pierce, and G. A. Poe, 1990: SSM/I instrument evaluation. IEEE Trans. Geosci. Remote Sens., 28, 781-790, https://doi.org/10.1109/36.58964.

Hou, A. Y., and Coauthors, 2014: The Global Precipitation Measurement Mission. Bull. Amer. Meteor. Soc., 95, 701-722, https://doi.org/10.1175/BAMS-D-13-00164.1.

Iguchi, T., and R. Meneghini, 2016: GPM_2AGPROFGPMGMI: GPM GMI (GPROF) radiometer precipitation profiling L2A 1.5 hours $13 \mathrm{~km}$ V05. Goddard Earth Sciences Data and Information Services Center, accessed 24 May 2017, https:// doi.org/10.5067/GPM/GMI/GPM/GPROF/2A/05.

JAXA, 2006: AMSR-E data users handbook. 4th ed. Japan Aerospace Exploration Agency, 115 pp., http://www.eorc.jaxa.jp/en/ hatoyama/amsr-e/amsr-e_handbook_e.pdf.

Jiang, H., J.P. Zagrodnik, C. Tao, and E.J. Zipser, 2018: Classifying precipitation types in tropical cyclones using the NRL $37 \mathrm{GHz}$ color product. J. Geophys. Res. Atmos., 123, 5509-5524, https:// doi.org/10.1029/2018JD028324.

Kidd, C., 1998: On rainfall retrieval using polarization-corrected temperatures. Int. J. Remote Sens., 19, 981-996, https://doi.org/ 10.1080/014311698215829.

Kummerow, C., W. Barnes, T. Kozu, J. Shiue, and J. Simpson, 1998: The Tropical Rainfall Measuring Mission (TRMM) sensor package. J. Atmos. Oceanic Technol., 15, 809-817, https://doi.org/ 10.1175/1520-0426(1998)015<0809:TTRMMT>2.0.CO;2.

Lee, T. F., F. J. Turk, J. Hawkins, and K. Richardson, 2002: Interpretation of TRMM TMI images of tropical cyclones. Earth Interact., 6, https://doi.org/10.1175/1087-3562(2002)006<0001: IOTTIO $>2.0 . \mathrm{CO} ; 2$.
Liu, C., E. J. Zipser, D. J. Cecil, S. W. Nesbitt, and S. Sherwood, 2008: A cloud and precipitation feature database from nine years of TRMM observations. J. Appl. Meteor. Climatol., 47, 2712-2728, https://doi.org/10.1175/2008JAMC1890.1.

Mohr, K. I., and E. J. Zipser, 1996: Defining mesoscale convective systems by their $85-\mathrm{GHz}$ ice-scattering signatures. Bull. Amer. Meteor. Soc., 77, 1179-1189, https://doi.org/10.1175/15200477(1996)077<1179:DMCSBT>2.0.CO;2.

Mroz, K., A. Battaglia, T. J. Lang, D. J. Cecil, S. Tanelli, and F. Tridon, 2017: Hail detection algorithm for the GPM core satellite sensors. J. Appl. Meteor. Climatol., 56, 1939-1957, https://doi.org/10.1175/JAMC-D-16-0368.1.

Nesbitt, S. W., E. J. Zipser, and D. J. Cecil, 2000: A census of precipitation features in the tropics using TRMM: Radar, ice scattering, and lightning observations. J. Climate, 13, 4087-4106, https:// doi.org/10.1175/1520-0442(2000)013<4087:ACOPFI>2.0.CO;2.

Price, C.G., and B.P. Murphy, 2002: Lightning activity during the 1999 Superior derecho. Geophys. Res. Lett., 29, 2142, https:// doi.org/10.1029/2002GL015488.

Spencer, R. W., H. M. Goodman, and R. E. Hood, 1989: Precipitation retrieval over land and ocean with the SSM/I: Identification and characteristics of the scattering signal. J. Atmos. Oceanic Technol., 6, 254-273, https://doi.org/ 10.1175/1520-0426(1989)006<0254:PROLAO>2.0.CO;2.

Todd, M. C., and J. O. Bailey, 1995: Estimates of rainfall over the United Kingdom and surrounding seas from the SSM/I using the polarization-corrected temperature algorithm. J. Appl. Meteor., 34, 1254-1265, https://doi.org/10.1175/15200450(1995)034<1254:EOROTU>2.0.CO;2.

Toracinta, E. R., D. J. Cecil, E. J. Zipser, and S. W. Nesbitt, 2002: Radar, passive microwave, and lightning characteristics of precipitating systems in the tropics. Mon. Wea. Rev., 130, 802-824, https://doi.org/10.1175/1520-0493(2002)130<0802: RPMALC $>2.0 . \mathrm{CO} ; 2$

Weinman, J. A., and P. J. Guetter, 1977: Determination of rainfall distributions from microwave radiation measured by Nimbus 6 ESMR. J. Appl. Meteor., 16, 437-442, https://doi.org/10.1175/ 1520-0450(1977)016<0437:DORDFM >2.0.CO;2.

Yang, S., J. Hawkins, and K. Richardson, 2014: The improved NRL tropical cyclone monitoring system with a unified microwave brightness temperature calibration scheme. Remote Sens., 6 , 4563-4581, https://doi.org/10.3390/rs6054563.

Zipser, E. J., C. Liu, D. J. Cecil, S. W. Nesbitt, and D. P. Yorty, 2006: Where are the most intense thunderstorms on Earth? Bull. Amer. Meteor. Soc., 87, 1057-1071, https://doi.org/10.1175/ BAMS-87-8-1057. 